Blocken B, Gualtieri C. 2012. Ten iterative steps for model development and evaluation applied to Computational Fluid Dynamics for Environmental Fluid Mechanics. Environmental Modelling \& Software 33: 1-22.

\title{
Ten iterative steps for model development and evaluation applied to Computational Fluid Dynamics for Environmental Fluid Mechanics
}

\author{
B. Blocken* (a) , C. Gualtieri ${ }^{(b)}$ \\ (a) Building Physics and Services, Department of the Built Environment, Eindhoven University of \\ Technology, P.O. box 513, 5600 MB Eindhoven, the Netherlands \\ (b) Hydraulic, Geotechnical and Environmental Engineering Department (DIGA), University of Napoli \\ Federico II, Via Claudio 21, 80125 Napoli, Italy
}

\section{Graphical abstract:}

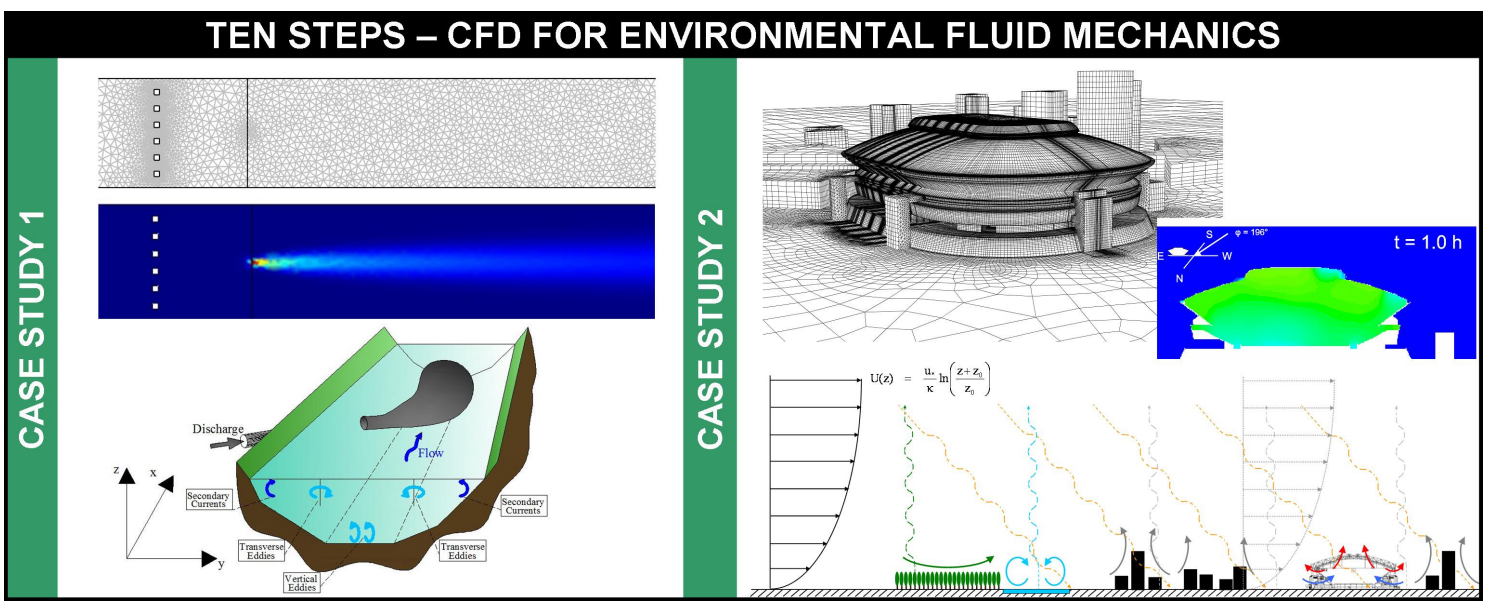

\section{Research highlights:}

- Application of the ten-steps approach to CFD in Environmental Fluid Mechanics (EFM)

- Existing best practice guidelines (BPG) in CFD mainly focus on only last three steps.

- Reason: specific character and disadvantages of CFD: need for verification and validation.

- More attention should be given to the other steps in CFD studies of EFM.

- Two case studies show that ten-steps approach is very well applicable to CFD in EFM and that it extends existing BPG.

* Corresponding author: Bert Blocken, Building Physics and Services, Eindhoven University of Technology, P.O.Box 513, 5600 MB Eindhoven, the Netherlands. Tel.: +31 (0)40 247 2138, Fax +31 (0)40 2438595

E-mail address: b.j.e.blocken@tue.nl 
Blocken B, Gualtieri C. 2012. Ten iterative steps for model development and evaluation applied to Computational Fluid Dynamics for Environmental Fluid Mechanics. Environmental Modelling \&

Software 33: 1-22.

\title{
Ten iterative steps for model development and evaluation applied to Computational Fluid Dynamics for Environmental Fluid Mechanics
}

\author{
B. Blocken* ${ }^{(a)}$, C. Gualtieri ${ }^{(b)}$ \\ (a) Building Physics and Services, Department of the Built Environment, Eindhoven University of \\ Technology, P.O. box 513, 5600 MB Eindhoven, the Netherlands \\ (b) Hydraulic, Geotechnical and Environmental Engineering Department (DIGA), University of Napoli \\ Federico II, Via Claudio 21, 80125 Napoli, Italy
}

\begin{abstract}
Computational Fluid Dynamics (CFD) is increasingly used to study a wide variety of complex Environmental Fluid Mechanics (EFM) processes, such as water flow and turbulent mixing of contaminants in rivers and estuaries and wind flow and air pollution dispersion in urban areas. However, the accuracy and reliability of CFD modeling and the correct use of CFD results can easily be compromised. In 2006, Jakeman et al. set out ten iterative steps of good disciplined model practice to develop purposeful, credible models from data and a priori knowledge, in consort with end-users, with every stage open to critical review and revision [Jakeman, A.J., Letcher, R.A., Norton, J.P., 2006. Ten iterative steps in the development and evaluation of environmental models. Environ. Modell. Softw. 21, 602-614]. This paper discusses the application of the ten-steps approach to CFD for EFM in three parts. In the first part, the existing best practice guidelines for CFD applications in this area are reviewed and positioned in the ten-steps framework. The second and third part present a retrospective analysis of two case studies in the light of the ten-steps approach: (1) contaminant dispersion due to transverse turbulent mixing in a shallow water flow and (2) coupled urban wind flow and indoor natural ventilation of the Amsterdam ArenA football stadium. It is shown that the existing best practice guidelines for CFD mainly focus on the last steps in the ten-steps framework. The reasons for this focus are outlined and the value of the additional - preceding - steps is discussed. The retrospective analysis of the case studies indicates that the tensteps approach is very well applicable to CFD for EFM and that it provides a comprehensive framework that encompasses and extends the existing best practice guidelines.
\end{abstract}

Keywords: Environmental Fluid Mechanics; air and water quality; river hydraulics; transverse mixing; wind flow; building aerodynamics

\section{Nomenclature}

Roman symbols

$\mathrm{C}_{\mu}, \mathrm{C}_{1 \varepsilon}, \mathrm{C}_{2 \varepsilon} \quad$ Constants in $\mathrm{k}-\varepsilon$ turbulence model

$\mathrm{C}_{\mathrm{S}} \quad$ Roughness constant

d Center-to-center spacing between elements of solid grid (m)

$\mathrm{D}_{\mathrm{t}-\mathrm{y}} \quad$ Transverse turbulent mixing coefficient $\left(\mathrm{m}^{2} / \mathrm{s}\right)$

h Flow depth (m)

$\mathrm{k} \quad$ Turbulent kinetic energy $\left(\mathrm{m}^{2} / \mathrm{s}^{2}\right)$

$\mathrm{k}_{\mathrm{S}} \quad$ Equivalent sand-grain roughness height $(\mathrm{m})$

$\mathrm{L}_{\mathrm{T}} \quad$ Turbulent length scale (m)

Q Volumetric airflow rate $\left(\mathrm{m}^{3} / \mathrm{s}\right)$

$\mathrm{Sc}_{\mathrm{t}} \quad$ Turbulent Schmidt number

$\mathrm{u}^{*} \quad$ Shear velocity $(\mathrm{m} / \mathrm{s})$

$\mathrm{U}_{\mathrm{T}} \quad$ Turbulent velocity scale $(\mathrm{m} / \mathrm{s})$

$\mathrm{V} \quad$ Indoor volume $\left(\mathrm{m}^{3}\right)$

W Channel width (m)

$\mathrm{x}, \mathrm{y}, \mathrm{z} \quad$ Cartesian coordinates $(\mathrm{m})$

* Corresponding author: Bert Blocken, Building Physics and Services, Eindhoven University of Technology, P.O.Box 513, 5600 MB Eindhoven, the Netherlands. Tel.: +31 (0)40 247 2138, Fax +31 (0)40 2438595

E-mail address: b.j.e.blocken@tue.nl 
Greek symbols

$\begin{array}{ll}\beta & \text { Constant in turbulent mixing coefficient equation } \\ \delta_{\mathrm{w}} & \text { Distance to wall for application of wall functions }(\mathrm{m}) \\ \varepsilon & \text { Dissipation rate of turbulent kinetic energy }\left(\mathrm{m}^{2} / \mathrm{s}^{3}\right) \\ \sigma_{\mathrm{k}}, \sigma_{\varepsilon} & \text { Constants in k- } \varepsilon \text { turbulence model } \\ \omega & \text { Specific dissipation rate }(1 / \mathrm{s})\end{array}$

Acronyms

$\begin{array}{ll}\text { ABL } & \text { Atmospheric Boundary Layer } \\ \text { ACH } & \text { Air Change rate per Hour } \\ \text { AIAA } & \text { American Institute of Aeronautics and Astronautics } \\ \text { AIJ } & \text { Architectural Institute of Japan } \\ \text { ASHRAE } & \text { American Society of Heating, Refrigerating and Airconditioning Engineers } \\ \text { ASME } & \text { American Society of Mechanical Engineers } \\ \text { CAD } & \text { Computer-Aided Design } \\ \text { CFD } & \text { Computational Fluid Dynamics } \\ \text { COST } & \text { Cooperation in Science and Technology } \\ \text { DNS } & \text { Direct Numerical Simulation } \\ \text { ECORA } & \text { Evaluation of Computational Fluid Dynamic Methods for Reactor Safety Analysis } \\ \text { EFM } & \text { Environmental Fluid Mechanics } \\ \text { ERCOFTAC } & \text { European Research Community on Flow, Turbulence and Combustion } \\ \text { GIS } & \text { Geographic Information System } \\ \text { HVAC } & \text { Heating, Ventilation and Air-Conditioning } \\ \text { LES } & \text { Large Eddy Simulation } \\ \text { NS } & \text { Navier-Stokes } \\ \text { RANS } & \text { Reynolds-Averaged Navier-Stokes } \\ \text { URANS } & \text { Unsteady Reynolds-Averaged Navier-Stokes }\end{array}$

\section{Introduction}

Computational Fluid Dynamics (CFD) methods were developed over 40 years ago by engineers and mathematicians to solve flow problems in the area of industrial engineering. While the fundamental equations of fluid motion that formed the basis of these methods had been known since the $19^{\text {th }}$ century, their solution for problems with complex geometries and boundary conditions required the development of efficient numerical solution techniques and the ability to implement those on computers. The development of both numerical techniques and digital machines with increasing computational power allowed in the last decades a wide application of CFD methods to many areas of fluid dynamics, including the realm of Environmental Fluid Mechanics (EFM). EFM is the scientific study of naturally occurring fluid flows of air and water on our planet Earth, especially those that affect the environmental quality of air and water (Cushman-Roisin et al. 2008). Scales of relevance within EFM range from millimeters to kilometers and from seconds to years. It should be noted that if classical fluid mechanics treats many different types of fluids under vastly different temperatures and pressures, by contrast EFM is almost exclusively concerned with only two bulk fluids, air and water, and moreover under a relatively narrow range of ambient temperatures and pressures. Also, while classical fluid mechanics tends to view turbulence as a negative element, because it creates unwanted drag and energy loss, EFM accepts turbulence as beneficial, because it favors rapid dispersion and dilution (Cushman-Roisin et al. 2008). Finally, EFM is aimed at prediction and decision. Indeed, typical problems in EFM concern the prediction of environmental-quality parameters that depend on natural fluid flows, such as bedload transports and pollution levels. EFM also extends into decision making. It is generally not aimed at design, but it may provide results useful in decision-making context. Decisions in the realm of EFM, however, in most cases do not address how natural fluid flows can be controlled or modified, but rather how inputs from human activities can be managed as to minimize their impact downstream.

Research methods in EFM include full-scale on-site experiments, full-scale laboratory experiments, reducedscale laboratory experiments in wind tunnels and water flumes, analytical and semi-empirical modeling and computer simulation with CFD. The main advantages of CFD are that it allows full control over the boundary conditions, that it provides data in every point of the computational domain simultaneously ("whole-flow field 
data") and that it does not suffer from potentially incompatible similarity requirements due to scaling limitations because simulations can be performed at full scale. CFD also allows efficient parametric analysis of different configurations and for different conditions. However, the accuracy and reliability of CFD are of concern and verification and validation studies are imperative. As a result, high-quality experiments to supply data for validation studies are also indispensible.

Within EFM, for many years CFD methods have found a wide application in the analysis of natural water systems, such as rivers, lakes, estuaries and coastal waters. Typical examples are the study of the flow and of the transport and mixing of contaminants and sediments within those systems as well as floodplain inundation modeling (Olsen 2001, Bates et al. 2005, Czernuszenko and Rowinski 2005). Also, CFD methods are sometimes applied in wastewater engineering (Karama et al. 1999, Hague et al. 2001, Peplinski and Ducoste 2002, Liu et al. 2004, Gualtieri 2006, Khan et al. 2006, Rauen et al. 2008, Stamou, 2008, Dufresne et al. 2009, Wols et al. 2010). Finally, in more recent times, CFD methods have been applied to the analysis of hyporheic flows, e.g. mixing flow between surface and subsurface waters due to spatial and temporal variations in channel characteristics (Bayani-Cardenas and Wilson 2007a, 2007b, Bayani-Cardenas et al. 2008, Bayani-Cardenas 2009, Jin et al. 2010, Endreny et al. 2011).

Within EFM, CFD has also been used extensively in research on wind flow and related processes in the outdoor environment around buildings, including pedestrian wind comfort (e.g. Stathopoulos and Baskaran 1990, Richards et al. 2002, Blocken et al. 2004, Yoshie et al. 2007, Mochida and Lun 2008, Tominaga et al. 2008a, Blocken and Persoon 2009, Blocken et al. 2012), wind-driven rain on building facades (e.g. Choi 1993, Etyemezian et al. 2000, van Mook 2002, Blocken and Carmeliet 2002, 2004, 2006, 2007, 2010, Tang and Davidson 2004, Briggen et al. 2009, Blocken et al. 2010, Huang and Li 2010, van Hooff et al. 2011a), air quality and pollutant dispersion around buildings (e.g. Tominaga et al. 1997, Leitl et al. 1997, Meroney et al. 1999, Canepa 2004, Meroney 2004, Chu et al. 2005, Hanna et al. 2006, Blocken et al. 2008a, Gromke et al. 2008, Yang and Shao 2008, Solazzo et al. 2009, Tominaga and Stathopoulos 2009, 2010, 2011, Balczo et al. 2009, Gousseau et al. 2011a, 2011b, Moonen et al. 2011), exterior building surface heat transfer (e.g. Blocken et al. 2009, Defraeye and Carmeliet 2010, Defraeye et al. 2010, 2011a, 2011b, Karava et al. 2011a), natural ventilation of buildings (e.g. Jiang and Chen 2002, Jiang et al. 2003, Heiselberg et al. 2004, Wright and Hargreaves 2006, Cook et al. 2008, Chen 2009, Norton et al. 2009, 2010, Hensen and Lamberts 2010, van Hooff and Blocken 2010a, 2010b, van Hooff et al. 2011b, Blocken et al. 2011, Ramponi and Blocken 2012), wind erosion (e.g. Tominaga and Mochida 1999, Parsons et al. 2004, Hussein and El-Shishiny 2009, Tominaga et al. 2011), wind energy (e.g. Milashuk and Crane 2011), wind loading on buildings (e.g. Tamura et al. 1997, Stathopoulos 1997, Selvam 1997, Tamura et al. 2008, Nozu et al. 2008) and other applications (e.g. Neofytou et al. 2006, Wakes et al. 2010).

CFD models are theory-based and process-based models. A comment needs to be made about the term model in the CFD framework. While CFD developers and physicists generally use the term model to describe the simplified physical representation of turbulent effects on the larger-scale flow or mean flow by turbulence models, CFD practitioners tend to use the same term to describe the (often also simplified) representation of the geometry under study, or the spatial and/or temporal discretization, or the boundary conditions, or any combination of the aforementioned parameters. In this paper, we will use the term model in the same respect as done by Jakeman et al. (2006), i.e. in a broad sense and encompassing the entire process, from code development to interpretation of model results.

Many large-scale environmental flows are turbulent, and a subdivision in CFD models can then be made based on the form of the governing equations that are solved to describe the turbulent flow. The four main classes distinguished in EFM are Direct Numerical Simulation (DNS), Large Eddy Simulation (LES), ReynoldsAveraged Navier-Stokes (RANS) and hybrid LES-URANS (unsteady RANS. DNS refers to solving the exact Navier-Stokes (NS) equations, down to the smallest length scales and time scales. For many applications in EFM, the associated Reynolds numbers are large to very large ( Re from $10^{4}$ up to $\left.10^{9}\right)$. As a result, DNS is too computationally demanding and one needs to resort to approximate forms of the NS equations, in which a degree of physical modeling is applied to reduce the physical complexity and the associated computational demand. In LES, the NS equations are filtered: only the eddies larger than a certain filter size are actually resolved, while the eddies smaller than this filter size are not resolved, but instead their effect on the larger eddies is approximated by a turbulence model (i.e. a so-called sub-grid scale model, as the grid or mesh size is often used as the filter). In RANS, only the mean (time-averaged or ensemble-averaged) flow is resolved, and the effect of all or most of the turbulence scales on the mean flow is modeled by a turbulence model. In the RANS approach two basic levels of modeling are currently used: eddy-viscosity models or first-order models and second-moment closure models (Hanjalić 2004). Each category has a number of variants. In addition, also hybrid LES-URANS methods have been developed and applied.

It is widely recognized that the results of CFD simulations can be very sensitive to the wide range of computational parameters that have to be set by the user. For a typical simulation, the user has to select the target variables, the approximate form of the governing equations, the turbulence model, the computational domain, the 
computational mesh, the boundary conditions, the discretization schemes, the convergence criteria, etc. During the past decades, many sensitivity tests and detailed verification and validation exercises have been conducted. While these efforts were fragmented at first, in the past ten years they have been combined into several extensive best practice guideline documents, which will be mentioned in section 2 of this paper.

In 2006, Jakeman et al. (2006) set out ten iterative steps of good disciplined model practice to develop purposeful, credible models from data and a priori knowledge, in consort with end-users, with every stage open to critical review and revision. While several previous papers had also provided information and steps for model development and evaluation, the paper by Jakeman et al. (2006) had the explicit intention to be more generic and to suggest guidelines for a wide range of model types, including empirical, data-based, statistical models, conceptual models based on assumed structural similarities to the system, agent-based models allowing locally structured emergent behavior, rule-based models, and specific theory-based or process-based models such as CFD. In 2008, Robson et al. (2008) published a paper in which they, in retrospect, evaluated the ten-steps approach for two case studies of process-based biogeochemical models of estuaries. They concluded that the tensteps approach is readily applicable to process-based aquatic biogeochemical modeling. They also highlighted the additional value generated by this retrospective exercise, and provided valuable feedback on the ten-steps approach itself. Additional follow-up papers were provided by Welsh (2008) and Piuleac et al. (2010), addressing groundwater modeling and modeling of electrolysis processes by neural networks, respectively.

The present paper provides a discussion of the ten-steps approach applied to CFD for EFM. Our paper is strongly inspired by the work by Jakeman et al. (2006) and Robson et al. (2008). The paper consists of three parts. In the first part, the existing best practice guidelines for CFD modeling of EFM are reviewed and positioned in the ten-steps framework. The second and third parts present a retrospective analysis of two case studies in the light of the ten-steps approach: (1) transverse turbulent mixing in a shallow water flow (Gualtieri 2010) and (2) coupled urban wind flow and indoor natural ventilation of the Amsterdam ArenA football stadium (van Hooff and Blocken 2010a). These two case studies were selected because of their large differences: water versus air as bulk fluid, two-dimensional (2D) versus three-dimensional (3D) modeling, finite-element versus control-volume technique and different turbulence models. These two case studies and their large differences serve to illustrate the wide applicability of the ten-steps approach for CFD in EFM.

\section{The ten-steps approach and best practice guidelines in CFD}

\subsection{The ten-steps approach}

The focus of the ten-steps approach is mainly on the questions that must be addressed, rather than on the alternatives that exist. As mentioned by Jakeman et al. (2006): "Whatever the type of modeling problem, certain common steps must be considered if the goals are credible results and knowledge acquisition, for the immediate purpose of the exercise and for the wider community and the longer term." Indeed, the ten steps are important in the pursuit of good practice in model development and application, which is essential for the credibility, acceptance and impact of models and their results, and for science and decision-making based on models. The following ten steps were defined:

(1) Definition of the purposes for modeling: This step is important because it is not necessarily easy to be clear about what the purposes are. Different stakeholders will have different degrees of interest in the possible purposes of a single model, such as gaining qualitative understanding of the system, knowledge elicitation and review, prediction or providing guidance for management and decision-making. Establishing the primary purposes of the modeling exercise is important because of their influence on the choices to be made at later stages.

(2) Specification of the modeling context: scope and resources: In this step the specific questions and issues to be addressed by the model are identified, as well as the available resources, the required outputs, the spatial and temporal scope, scale and resolution, the model flexibility and the users of the model.

(3) Conceptualization of the system, specification of data and other prior knowledge: "Conceptualization refers to basic premises about the working of the system being modeled." (Jakeman et al. 2006). The data, prior knowledge and assumptions of the processes need to be defined, based on the prior identification of model purposes.

(4) Selection of model features and families: Based on the preceding three steps, the types of variables and the nature of their treatment are selected, as well as the links between system components and processes, which includes the modeling approach, conceptual model and spatial and temporal scales.

(5) Choice of how model structure and parameters values are to be found, which can be done by prior science-based theoretical knowledge and/or empirical data.

(6) Choice of estimation performance criteria and technique, where these criteria should reflect the overall aims and purposes of the modeling activity. 
(7) Identification of model structure and parameters, which is generally an iterative process involving hypothesis testing of alternative model structures, with the underlying aim to balance sensitivity to system variables against complexity of representation.

(8) Conditional verification including diagnostic checking, which includes testing if the model is "sufficiently insensitive to possible but practically insignificant changes in the data and to possible deviations of the data and system from the idealizing assumptions made... It is also necessary to verifiy that the interactions and the outcomes of the model are feasible and defensible, given the objectives and prior knowledge." (Jakeman et al. 2006).

(9) Quantification of uncertainty, which is particularly important in large, integrated models, and which should be considered in the context of the purposes of the model.

(10) Model evaluation or testing (other models, algorithms, comparisons with alternatives), which implies evaluating the model is the light of its objectives. Robson et al. (2008) elaborated on this step and suggested different questions to be considered:

- How well does the model reproduce an independent data set?

- How well does the model perform under unusual conditions?

- Is the complex model better than a simpler one?

- Can the model be used to improve understanding of underlying system function?

- Finally, and most importantly, does the model help to answer questions about the system function and can it be used to make predictions about the future?

\subsection{Best practice guidelines in $C F D$}

Whereas in the area of industrial engineering the systems are closed and boundary conditions, problem geometry and material properties of any solid surfaces are usually well known, the application of CFD methods to the EFM area involves many different issues related to the existing uncertainty of geometry and boundary conditions, drag coefficients, driving forces and the interactions among different processes and inputs. These uncertainties involve almost every aspect of the modeling process and it may therefore be very difficult to assess model performance. This implies that CFD application to environmental flows may have research priorities very different from other CFD applications.

Several studies have been presented in order to establish best practice guidelines in CFD studies. In 1993 the American Society of Mechanical Engineers (ASME) proposed ten guidelines on the control of numerical accuracy for CFD manuscripts submitted to the journal (ASME 1993). Among others, the authors were required to be precise in describing the numerical method used and to demonstrate mesh-independent or mesh-convergent results by presenting solutions over a range of significantly different mesh resolutions. Also, clear statements defining the methods used to implement boundary and initial conditions and comparison with appropriate analytical or well-established numerical benchmark solutions and with reliable experimental results were required (ASME 1993). Roache (1997) discussed the quantification of uncertainty in CFD methods, pointing out the difference between verification, which means solving the equations right, and validation, which is solving the right equations, concluding that a code cannot be validated, but only a calculation or a range of calculations with a code can be validated. This theme was also addressed by Stern et al. (2001). They distinguished between verification, which is a process for assessing numerical simulation uncertainty and, when conditions permit, estimating the sign and magnitude of the numerical error itself and the uncertainty in that error estimate, and validation, which is a process for assessing simulation modeling uncertainty by using benchmark experimental data and, when conditions permit, estimating the sign and magnitude of the modeling error itself. Roache (2009) noted that calibration, which is the adjustment or tuning of free parameters in a model to fit the model output with experimental data, which is a sometimes necessary component of model development, is not to be considered as validation, unless when the previously calibrated model predictions are evaluated against a set of data not used in the tuning.

Extensive guides and standards on verification and validation of CFD simulations were published in 1998 by the AIAA $^{1}$ (1998) and in 2009 by the ASME (ASME 2009). Extensive papers on verification, validation and predictive capability in computational engineering and physics - which include CFD - were provided by Oberkampf et al. (2004) and by Roy and Oberkampf (2010).

In addition, also best practice guidelines covering a wider area than only verification and validation were developed. In 2000, the ERCOFTAC ${ }^{2}$ Special Interest Group on Quality and Trust in Industrial CFD published an extensive set of best practice guidelines for industrial CFD users (Casey and Wintergerste 2000). These guidelines focused on RANS simulations. Although they were not specifically intended for EFM, many of these guidelines also apply for CFD simulations in EFM. A lot of attention in the guidelines is devoted to avoiding

\footnotetext{
${ }^{1}$ AIAA $=$ American Institute of Aeronautics and Astronautics

${ }^{2}$ ERCOFTAC $=$ European Research Community on Flow, Turbulence and Combustion
} 
errors and uncertainties in CFD simulations from the perspective of the user of an already developed CFD code. Indeed, while there is a general consensus about the main physical modeling approaches (DNS, LES, RANS) and even on a wide range of turbulence models, the advantages and disadvantages of which are well documented in the scientific literature, it is considered that maybe the largest errors and uncertainties are caused by the user of the code. Within the project ECORA ${ }^{3}$, Menter et al. (2002) published best practice guidelines based on the ERCOFTAC guidelines, but modified and extended specifically for CFD code validation.

In the area of EFM studies applied to natural water systems, some criteria for the application of CFD codes to open channel flows were proposed by Knight et al. (2005) within a comparative study between different RANSbased approaches to simulate the 3D flow in a prismatic channel. Lane et al. (2005) developed the guidelines specified by ASME for the specific case of open channel flows. In doing so, they demonstrated that the ASME criteria may not be sufficient for many practical fluvial applications, but however can provide a minimum framework. In particular, Lane et al. (2005) argued that ASME criterion 10 on model validation should be replaced by a more comprehensive framework based on sensitivity analysis, benchmarking and flow visualization.

In the area of EFM studies applied to wind flow around buildings, early sensitivity, verification and validation studies have provided a lot of valuable information (e.g. Murakami and Mochida 1989, Baetke et al. 1990, Stathopoulos and Baskaran 1990, Cowan et al. 1997, Hall 1997). However, initially this information was dispersed over a large number of individual publications in different journals, conference proceedings and reports. Later, compilation efforts were undertaken, including the work by Scaperdas and Gilham (2004), Bartzis et al. (2004) and the comprehensive review paper by Franke et al. (2004). Later, Franke et al. (2007) extended their review paper into an extensive "Best Practice Guideline for the CFD simulation of flows in the urban environment", in the framework of the $\mathrm{COST}^{4}$ Action 732: Quality Assurance and Improvement of Microscale Meteorological Models. Like the ERCOFTAC guidelines, also these guidelines were primarily focused on steady RANS simulations, although also some limited information on URANS, LES and hybrid LES-URANS was provided. When using CFD tools, whether they are academic/open source or commercial codes, it is also important that the code is well documented, and that basic verification tests and validation studies have been successfully performed and reported. A good description of how a microscale airflow and dispersion model has to be documented can be found in the Model Evaluation Guidance Document published in the COST Action 732 by Britter and Schatzmann (2007).

In Japan, working groups of the Architectural Institute of Japan (AIJ) conducted extensive cross-comparisons between CFD simulation results and high-quality wind tunnel measurements to support the development of guidelines for practical CFD applications. Part of these efforts was reported by Yoshie et al. (2007). In 2008, Tominaga et al. (2008b) published the "AIJ guidelines for practical applications of CFD to pedestrian wind environment around buildings", and Tamura et al. (2008) wrote the "AIJ guide for numerical prediction of wind loads on buildings". While the former document focused on steady RANS simulations, the latter also considered LES, given the importance of time-dependent analysis for wind loading of buildings and structures.

In addition to these general guidelines, also some very specific guidelines were published. These include (1) consistent modeling of equilibrium atmospheric boundary layers in computational domains (e.g. Richards and Hoxey 1993, Blocken et al. 2007a, 2007b, Franke et al. 2007, Hargreaves and Wright 2007, Gorlé et al. 2009, Yang et al. 2009); (2) high-quality mesh generation (e.g. Tucker and Mosquera 2001, van Hooff and Blocken 2010a) and (3) validation with field and laboratory data (e.g. Schatzmann et al. 1997, Schatzmann and Leitl 2011).

The establishment of these guidelines has been a very important step towards more accurate and reliable CFD simulations. Furthermore, it is advisable that future best practice guidelines for CFD applications in the EFM field will include a larger application of benchmarking because it provides relevant information for reliable comparison among different CFD techniques and approaches. So specific benchmarks should be developed in the different contexts and practical applications of CFD methods for EFM.

\subsection{Best practice guidelines in CFD in the framework of the ten-steps approach}

As mentioned earlier, the ten-steps approach was developed with the explicit intention to be generic and to suggest guidelines for a wide range of model types. While all ten steps are relevant for CFD in EFM, the main focus of the existing best practice guidelines in CFD is clearly on the last three steps, addressing verification, uncertainty and validation. Two main reasons are responsible for this.

(1) The first reason is the generic character of the ten-steps approach versus the more specific character of CFD. Actually, the choice to use CFD as a modeling approach is a possible outcome of step 4 of the ten-steps approach (selection of model features and families). Indeed, other and more simplified modeling approaches

\footnotetext{
${ }^{3}$ ECORA = Evaluation of Computational Fluid Dynamic Methods for Reactor Safety Analysis

${ }^{4} \mathrm{COST}=$ Cooperation in Science and Technology
} 
exist for EFM, although in many cases there is a clear preference in the EFM community for CFD. The reasons for this preference are the same as clearly outlined by Robson et al. (2008) in their discussion of the advantages of process-based models: "(i) these models explicitly represent understanding and functionality of the system, that is, not only its responses, but also its internal dynamics, and allow this understanding to be tested; (ii) they allow for a detailed, quantitative simulation of the current behavior of the system; and (iii) they provide a means to predict responses to changes, even (with caution) when those changes take the system beyond its measured historical variability."

(2) The second reason is directly associated with the disadvantages of process-based models mentioned by Robson et al. (2008): "they tend to have high data input requirements and a high level of complexity, and they may have high computational costs, all of which can make it difficult to quantitatively estimate the uncertainty of the predictions." The high data input requirements and high level of complexity of CFD impose a strong need for verification, validation and uncertainty analysis. Therefore, it is not surprising that these have been the main focus in the development of the existing best practice guidelines in CFD.

Apart from their main focus on the last three steps, the existing CFD best practice guidelines are also related to items of step 1 (selection of target variables), step 2 (extent of model, time and spatial intervals), step 3 (prior knowledge and parameter values), step 4 (choice of sub-model LES, RANS, hybrid LES-URANS and turbulence models, spatial and/or temporal resolution), step 5 (boundary conditions, sub-models and turbulence parameter values from laboratory and field studies, etc.), step 6 (choice of performance criteria) and step 7 (selection of modeled processes, initialization, etc.). In the next two sections, it will indeed be shown that each of the ten steps could be properly applied to CFD. Therefore, it can be stated that the ten-steps approach provides a comprehensive framework that encompasses the existing best practice guidelines but that also provides valuable additional advice for the development, application and evaluation of EFM CFD models and their results.

It is important to note that for CFD codes, previously performed verification and validation studies can provide important information on the accuracy and reliability of these codes for future and similar studies, and can therefore support the verification and validation activities in steps 8-10.

\section{Case study 1: transverse turbulent mixing in a shallow water flow}

This case study was presented in detail in the paper [Gualtieri C. 2010. RANS-based simulation of transverse turbulent mixing in a 2D geometry. Environmental Fluid Mechanics 10(1-2), 137-156] (Gualtieri 2010). Since it is not the intention herein to fully describe the models and algorithms used and/or the conclusions drawn from the numerical results, the interested reader is referred to the above manuscript. Rather this numerical study is herein analyzed in the light of the ten-steps approach. Thus, each of the sections below refers to one of the ten steps.

\subsection{Definition of the purposes for modeling}

One of the most common purposes of a modeling effort is gaining a better qualitative understanding of a system or process. This is the purpose of the case study analyzed here. Although the transverse mixing process is of significant importance when dealing with wastewater treatment plant discharges, cooling water returns and the mixing of tributary inflows, this process has received less attention by researchers than longitudinal mixing (Rutherford 1994). In such situations, since steady-state conditions are approximated (i.e. temporal concentration gradients are small), the spreading across the channel is important and accurate modeling and prediction of transverse mixing is required (Boxall and Guymer 2003). Also, it is well known that transverse mixing is important in determining the rate of longitudinal mixing because it tends to control the exchange between regions of different longitudinal velocity. Despite its importance, no established theory exists to predict transverse mixing rates. The turbulent diffusion coefficient and its dependence on the various flow parameters must be determined from experimental work, but numerical simulations could be a feasible alternative to be evaluated.

In this case study numerical simulations were undertaken to simulate the transverse mixing of a steady-state point source of a tracer in a 2D rectangular geometry, which is expected to reproduce a shallow flow (Fig. 1). A shallow flow can be defined as a predominantly horizontal flow in a fluid domain for which the two horizontal dimensions greatly exceed the vertical dimension (Jirka 2001). The specific purposes of this study were:

- to investigate the ability of a 2D RANS-based approach to reproduce the transverse turbulent mixing in a shallow flow. More specifically, the standard k- $\varepsilon$ turbulence model (Jones and Launder 1972) was used. It is the easiest to implement and the most economical in computation despite its limitations inherent to the hypothesis of isotropic turbulence that was expected to lead to an overestimation of transverse mixing (Section 3.7). Numerical results for tracer concentration were used to obtain the transverse turbulent mixing coefficient $\mathrm{D}_{\mathrm{t}-\mathrm{y}}$. Numerical results for $\mathrm{D}_{\mathrm{t}-\mathrm{y}}$ were also compared with experimental data collected by Lau and Krishnappan (1977) in a rectangular flume. They measured the mixing process of a tracer 
continuously discharged from a constant head injection apparatus into the middle of the flume at approximately mid-depth $11 \mathrm{~m}$ downstream from the beginning of the flume. The tracer concentrations were measured at mid-depth downstream of the injection point by using a single electrode conductivity probe. The probe was moved along the channel width to derive cross-stream concentration distributions;

- to assess the effect of a grid formed by square components located upstream of the point of injection on transverse turbulent mixing (Fig. 1 - Geometry B). Since experimental data for this case were missing, the results from the experimental work by Rummel et al. (2005) for threedifferent grid geometries were considered for a qualitative assessment of the numerical results.

These objectives are consistent with some of the purposes mentioned by Jakeman et al. (2006). The first objective directly fits with purposes such as gaining a better qualitative understanding of the system, prediction (extrapolation from the past), knowledge elicitation and review. The second objective, related to the effects of a grid on turbulent mixing, could be considered as aiming at prediction (what if exploration). Finally, it should be noted that $\mathrm{D}_{\mathrm{t}-\mathrm{y}}$ was calculated from the numerical concentration field using different approaches. In this sense, another point indicated in Jakeman et al. (2006), i.e. interpolation: estimating variables which cannot be measured directly (state estimation), was addressed in the study.

\subsection{Specification of the modeling context: scope and resources}

\subsubsection{Available resources}

The undertaken numerical simulations were intended to reproduce transverse turbulent mixing in a shallow water flow and, in particular, the experimental work conducted by Lau and Krishnappan (1977) in a rectangular flume. Therefore, the first available resource was the geometry used by Lau and Krishnappan, while the second resource was the Comsol Multiphysics 3.4 ${ }^{\mathrm{TM}}$ (2008) modeling package, which is a commercial multiphysics modeling environment.

Lau and Krishnappan conducted their experiments in a rectangular flume of $30.7 \mathrm{~m}$ long and $0.60 \mathrm{~m}$ wide. Extra sidewalls were installed to convert the flume to $0.45 \mathrm{~m}$ or $0.30 \mathrm{~m}$ width. The adopted numerical geometries were based on the view from above, i.e. in the $\mathrm{x}-\mathrm{y}$ plan, of the Lau and Krishnappan flume. They were $40 \mathrm{~m}$ long and $0.60 \mathrm{~m}$ wide. The point of injection was located $11 \mathrm{~m}$ downstream of the inflow section. Furthermore, in Geometry B there was a grid formed by 6 square components, each with dimension $0.02 \times 0.02 \mathrm{~m}^{2}$, with a centerto-center spacing $\mathrm{d}=0.06 \mathrm{~m}$. The grid was located $0.5 \mathrm{~m}$ upstream of the point of injection. In Geometry A the square grid was absent.

Different mesh characteristics were tested. After that, the mesh generation process was made assuming, among others, a constant value for the element growth rate, which determines the maximum rate at which the element size can grow from a region with small elements to a region with larger elements (Comsol Multiphysics 2008). The value must be greater than or equal to 1 . For both Geometry A and B, different values for the maximum element size were selected for the geometry upstream and downstream the point of injection (Fig. 2). Smaller values were selected downstream of this point to better capture transverse mixing. Also, at the square grid components in Geometry B, the maximum element size was smaller than the maximum element size at the walls, for both Geometry A and B. The mesh was made by triangular elements and mesh quality visualization demonstrated a quite uniform quality of the elements of the mesh.

The commercial multiphysics modeling environment Comsol Multiphysics 3.4 ${ }^{\mathrm{TM}}$ was applied. Previous studies have demonstrated its capability to simulate both flow and concentration field within EFM applications with good results, such as in the case of the backward-facing step flow (Gualtieri 2005), a contact tank (Gualtieri 2006), a drinking water tank (Gualtieri 2009) and a river with a square dead zone (Gualtieri et al. 2010).

\subsubsection{Forcing variables and required outputs}

At the inlet an inflow type boundary condition was applied with a uniform velocity profile. Also inlet turbulent intensity and length scale were assigned. Turbulent intensity was set to 5\%, which corresponds to a fully turbulent flow. Usually, turbulence intensity can be derived from the Reynolds number. The turbulent length scale is a physical quantity related to the size of the large eddies that contain most of the energy in turbulent flows. Also it is a measure of the size of the turbulent eddies that are not resolved (Comsol Multiphysics 2008). For fully-developed channel flows, this parameter can be approximately derived as $0.07 \times W$, where $W$ is the channel width.

The required outputs were first of all the parameters of the averaged flow field, such as pressure, velocity components and k- $\varepsilon$ turbulence model parameters. Finally, from the solution of the advection-diffusion equation the averaged tracer concentration within the flow domain was obtained.

\subsubsection{Spatial and temporal scope, scale and resolution}


The numerical study was carried out with steady-state conditions for both the flow and concentration fields.

The computational domain for both Geometry A and Geometry B and part of the mesh are presented in Fig. 1 and Fig. 2. Different spatial scales were applied in the domain. Maximum element sizes were $0.1 \mathrm{~m}$ and $0.05 \mathrm{~m}$ in the upstream and downstream region, respectively. Also, for both Geometry A and B, at the walls, the maximum element size was $0.05 \mathrm{~m}$, whereas, at the square grid components in Geometry $\mathrm{B}$, the maximum element size was $0.01 \mathrm{~m}$. The resulting meshes for geometry A and B had 35124 and 37284 triangular elements (Fig. 2).

\subsubsection{Users of the model and model flexibility}

The mixing of contaminants in streams and rivers is a significant problem in EFM and river engineering because the understanding of the impact and the fate of pollutants in these water bodies is a primary goal of water quality management. Since most rivers have a high aspect ratio, that is the width to depth ratio, discharged pollutants become vertically mixed within a short distance from the source and vertical mixing is only important in the socalled near-field (Rutherford 1994). In the mid-field, the vertical concentration gradients are negligible and both subsequent transverse and longitudinal changes of the depth-averaged concentrations of the pollutants should be addressed. Thus, the model could be applied as a preliminary tool to identify the length needed to reach the transverse mixing of a contaminant continuously injected in a shallow turbulent flow.

Concerning model flexibility, it should be noted that it would be easy to change the location of the tracer source, i.e. moving it on the walls of the geometry, as well as to consider a reactive solute or change the characteristics of the square components forming the grid.

\subsection{Conceptualization of the system, specification of data and other prior knowledge}

Conceptualization of a system refers to the identification of the basic processes controlling its behavior. Concerning the presented case study, it is believed that transverse or lateral mixing is due to the following causes (Rutherford 1994) (Fig. 3):

- turbulence generated by the channel boundaries, which involves many eddies of various sizes and intensities, all embedded in one another (Pope 2000). These eddies are responsible for both momentum and mass transfer, according to the Reynolds analogy, resulting in contaminant mixing far exceeding that occurring at the molecular scale. Also it could be expected that in a turbulent flow the largest eddies regulate the rate of turbulent diffusion. In a river, lateral mixing is due to the transverse eddies that rotate horizontally, about a vertical axis;

- vertical variations in the transverse velocity (velocity shear), which are significant in the vicinity of channel banks and further contribute to transverse spreading of contaminants;

- secondary currents, which cause contaminants to move in opposite directions at different depths increasing the rate of mixing (Henderson 1966).

Prediction of transverse mixing rate is needed when using the 2D depth-averaged advection-diffusion equation in the mid-field (Rutherford 1994). In this equation, both transverse turbulent diffusion and transverse dispersion coefficients are present, which represent spreading of the solute in the lateral direction. Also, the effects of the secondary currents might play a role. To overcome the inherent complexity of the process, as per step 3 of the procedure proposed by Jakeman et al. (2006), one should decide what to include and what can be simplified or neglected in the modeling of transverse turbulent mixing. Since in field observations it is difficult to distinguish the specific effect of each of these processes on contaminant spreading in the lateral direction, their overall effect is usually combined for convenience into a single mixing coefficient, $\mathrm{D}_{\mathrm{ty}}$, whose estimation is one of the objectives of this numerical study. Modeling transverse turbulent mixing is a good example of conceptualization where a group of different processes is taken into account by only one coefficient.

Since no established theory exists to predict transverse mixing rates in open channel flows, $\mathrm{D}_{\text {ty }}$ and its dependence on the various flow parameters must be determined from experimental work. A good number of experimental studies are available in the literature and some literature-based empirical predictive equations for $\mathrm{D}_{\mathrm{t}-\mathrm{y}}$ are available for cases of straight rectangular channels, gently meandering naturals channels and curved channels and rivers bends (Rutherford 1994, Gualtieri and Mucherino 2007, 2008). They provide further prior knowledge on this process.

Finally, prior knowledge on this process, as for any system in EFM, includes at least conservation of mass, both for the fluid and for the solute, and conservation of momentum and energy. 


\subsection{Selection of model features and families}

\subsubsection{Modeling approach and conceptual model}

Major features in the modeling approach are the types of variables covered and the nature of their treatment, e.g. white/black/grey box, lumped/distributed, linear/non-linear, stochastic/deterministic, which place the model in a particular family or families (Jakeman et al. 2006).

As pointed out above, since no established theory exists to predict transverse mixing rates even in these channels, the turbulent diffusion coefficient and its dependence on the various flow parameters must be determined from experimental studies (Rutherford 1994, Gualtieri 2010). From dimensional reasoning it is possible to relate any turbulent mixing coefficient to a turbulent length and a velocity scale, $\mathrm{L}_{\mathrm{T}}$ and $\mathrm{U}_{\mathrm{T}}$, respectively, as:

$D_{t-y}=L_{T} U_{T}$

In a plane shear flow, turbulence is generated by vertical velocity shear which arises as a result of bed friction. Since the shear velocity $u^{*}$ is a measure of bed friction, it could be selected as velocity length scale in Eq. (1). This is also consistent with the literature on vertical diffusivity and longitudinal dispersion coefficients (Rutherford 1994). There is indeed some controversy about the proper length scale to be used in Eq. (1). It is most common to assume the flow depth $\mathrm{h}$ as the length scale for transverse diffusivity too, that is $\mathrm{h}=\mathrm{L}_{\mathrm{T}}$, since this parameter controls the largest vertical eddies (Rutherford 1994, Gualtieri 2010). Therefore, Eq. (2) yields:

$D_{t-y}=\beta h u^{*}$

where $\beta$ is a constant that is derived from the analysis of experimental data and that depends on the river characteristics (Rutherford 1994). Numerical simulations of the transverse turbulent mixing process using different approaches are reported in the literature (Boxall and Guymer 2003, Shiono et al. 2003, Duan 2004, Ahmad 2008, Zhang and Shen 2008, Won Seo et al. 2009). They gained a detailed and complete definition of the whole flow and concentration field instead of a rough estimate of the transverse turbulent mixing coefficient, as allowed by Eq. (2). Also, numerical simulations provide an estimation of $\mathrm{D}_{\mathrm{t}-\mathrm{y}}$ in each section of the geometry. Furthermore, empirical equations predicting the effect of a grid on transverse turbulent mixing are missing in the literature, so in these cases numerical simulation is the only feasible alternative to experimental methods. The main disadvantage of CFD methods was the time-consuming effort to prepare and run the numerical simulations as well as the post-processing of simulated concentration data. Finally, a critical point was the choice of the modeling approach to be applied since turbulent flows can be simulated at different levels of detail. This point will be mainly explained in Section 3.5.

\subsubsection{Spatial scales}

In Section 3.2.3, it was highlighted that different mesh characteristics were assigned in the flow domain. In this sense, within the flow domain a distinction can be made between four spatial zones with different spatial resolution modeling:

- the zone upstream of the tracer injection, where no tracer was present since at the inlet, a concentration type boundary condition was applied, assuming zero concentration entering the domain;

- the walls, where a logarithmic law of the wall boundary condition was applied. It is well-known that turbulent flows are significantly affected by the presence of walls. Turbulent eddies are distorted and constrained in size, being compressed in the wall-normal direction and elongated in the streamwise direction (Sotiropoulos 2005). The classical k- $\varepsilon$ model due to its basic hypothesis of isotropy needs to be modified to account for the effect of the walls on the local structure of turbulence. To account for solid walls, the wall function approach was applied to bridge the viscosity-affected region between the wall and the fully-turbulent region;

- the zone downstream of the tracer injection, where transverse turbulent mixing occurred. Thus, a spatial resolution smaller than that in zone upstream of the injection was assumed;

- the zone around the square grid components in Geometry B. In this zone, the smallest spatial resolution within the simulated domain was applied. At the square grid components, a logarithmic law of the wall boundary condition was applied. 


\subsection{Choice of how model structure and parameter values are found}

This point addresses a logical further step after the selection of model features and families, that is the definition of the structure of the model, including the form of the relations between the variables in the model (Jakeman et al. 2006). Thus, these variables should be clearly identified. In Section 3.2.2, it was pointed out that the variables of interest in the numerical study were all the parameters of the averaged flow field, such as pressure, velocity components and k- $\varepsilon$ turbulence model parameters, and the parameters of the averaged concentration field, such as turbulent fluxes and concentration. The relations among these parameters are provided by the classical conservation laws for mass and momentum. They are expressed in the form of partial differential equations. In turbulent flow, these equations can be solved using different approaches, as discussed in Section 1. In this study the RANS approach was selected, as discussed below in Section 3.7. Thus, all the parameters of interest were obtained by solving the Reynolds-averaged conservation of mass law, both for the fluid and the tracer, and the Reynolds-averaged conservation of momentum law. For turbulence closure, the standard k- $\varepsilon$ turbulence model was applied to derive the eddy viscosity values in the flow domain. From the concentration data, using different methods, such as the method of moments (Rutherford 1994), the method based on the transverse profile of turbulent kinematic viscosity and the method based on the mixing index (Rutherford 1994), the values of the transverse $\mathrm{D}_{\mathrm{t}-\mathrm{y}}$ were estimated.

Note that the five numerical constants in the standard k- $\varepsilon$ turbulence model, $\mathrm{C}_{\mu}, \sigma_{\mathrm{k}}, \sigma_{\varepsilon}, \mathrm{C}_{1 \varepsilon}$ and $\mathrm{C}_{2 \varepsilon}$, were set to their default values, which were derived from fitting to experimental data for a large range of turbulent flow cases. Also, for the solution of the turbulent advection-diffusion equation the value of the turbulent Schmidt number $\mathrm{Sc}_{\mathrm{t}}$ must be defined. This is a key parameter for modeling the transport of solutes and different approaches were proposed. Following the Reynolds analogy, which is based on the assumption that the turbulent diffusivities for momentum and mass are similar since they all depend on the same eddies for transport, the value of $\mathrm{Sc}_{\mathrm{t}}$ was set equal to 1 . To account for solid walls, the wall-function approach was applied to bridge the viscosity-affected region between the wall and the fully-turbulent region. This approach is expected to be accurate for high Reynolds numbers and situations where pressure variations along the walls are not very large. However, it can often be used outside its frame of validity with reasonable success (Comsol Multiphysics 2008). In particular, logarithmic wall functions applied to finite elements assume that the computational domain begins at a distance $\delta_{\mathrm{w}}$ from the real wall. This parameter should have a dimensionless value from 30 and 100 and in this study it was set equal to 100 .

\subsection{Choice of estimation performance criteria and technique}

The parameter estimation criteria reflect the desired properties of the estimates (Jakeman et al. 2006) and, in a broader sense, the overall and specific purposes of the model. The two main purposes of the numerical effort were listed in Section 3.1. The first purpose of the case study was to investigate the ability of a 2D RANS-based approach to reproduce the transverse turbulent mixing in a shallow flow. Numerical results for tracer concentration were used to obtain $\mathrm{D}_{\mathrm{t}-\mathrm{y}}$. The simulation results for $\mathrm{D}_{\mathrm{t}-\mathrm{y}}$ were also compared with experimental data collected by Lau and Krishnappan (1977) in a rectangular flume. Therefore, the agreement between numerical result and experimental data for $\mathrm{D}_{\mathrm{t}-\mathrm{y}}$ was considered as a performance criterion. The second purpose of the case study was to assess the effect of a grid formed by square components, located upstream of the point of injection, on transverse turbulent mixing. Since experimental data for this case were missing, the results from the experimental study carried out by Rummel et al. (2005) for three different grid geometries were considered for a qualitative assessment of the numerical results. This qualitative assessment referred to the enhancement of transverse mixing due to the introduction of a grid upstream of the injection point (grid-turbulence transverse mixing).

Note that additional criteria for the estimation of model performance could be a comparison of different parameters, such as flow velocities, tracer concentration and fluxes, if the experimental data for these parameters were available.

\subsection{Identification of model structure and parameters}

Whereas steps 5 and 6 discussed the choice of methods for finding model structure and parameters and criteria and techniques for estimating model performance, respectively, the present step addresses the iterative process of finding a suitable model structure and parameter values (Jakeman et al. 2006).

The main issue was the choice of a suitable model approach for simulating transverse mixing in a shallow flow. This type of flow can be defined as having a lateral extent greater than its vertical confinement, as is the case in natural rivers, estuaries, stratified layers in lakes, the upper ocean and even for large-scale motions in the oceans. In shallow flow, turbulent fields can be considered as homogeneous and stationary in the horizontal plane and mixing is governed by 2D coherent structures (Rummel et al. 2005). It is well-known that turbulent 
flows can be simulated at different levels of detail distinguishing between the resolved part and the modeled part (Hanjalić, 2004, Van Prooijen and Uijttewaal 2005). At the lowest level of detail, only the mean flow is resolved. The turbulence is modeled using a turbulence model, based on the time-averaged flow properties. This level corresponds to the approach based on RANS equations. Recent studies demonstrated that for simplified cases, where mean velocities and bulk mixing properties are needed, RANS-modeling of shallow flows is still appropriate (Van Prooijen and Uijttewaal 2005). However, within the RANS-based approach, several turbulence models are available (Section 1). Among the turbulence models based on the eddy-viscosity concept, the k- $\varepsilon$ models, the k- $\omega$ models and their variations (Menter 1994, Wilcox 1998) are most widely used and this is largely due to their ease of implementation, economy in computation and, most importantly, being able to obtain reasonable accurate solutions with the available computational power. However, several shortcomings have been discovered over three decades of use and validation. In open channel flows modeling, it is known that in the case of prismatic channels where there are no geometrical variations along the channel, the k- $\varepsilon$ turbulence model fails to predict any evidence of secondary flow. This is because the mean secondary flow is driven by the anisotropy of the Reynolds stresses (Moinuddin et al. 2004, 2011), while the k- $\varepsilon$ model assumes that the turbulence is isotropic. Also, the assumption of isotropy may lead the k- $\varepsilon$ model to predict large turbulent viscosity and, consequently, high turbulent diffusivities. Despite these issues, in this study the standard k- $\varepsilon$ turbulence model was selected to take advantage of its ease of implementation and economy in computation and to test its capability to simulate transverse turbulent mixing in a shallow flow.

\subsection{Conditional verification including diagnostic checking}

Jakeman et al. (2006) pointed out that quantitative verification of a model may be undertaken using different criteria, which are mostly based on a comparison between the model results and observed data, while qualitative verification preferably involves knowledgeable data suppliers or model users who are not modelers themselves.

In this numerical study only a quantitative verification was made, using the available experimental data from Lau and Krishnappan (1977). This issue is discussed in detail in Section 3.10.

\subsection{Quantification of uncertainty}

Uncertainty must be considered in developing and applying any model. As highlighted by Jakeman et al. (2006), uncertainty in models stems from incomplete system understanding (which processes to include, which processes interact), from imprecise, finite and often sparse data and measurements and from uncertainty in the baseline inputs and conditions for model runs, including predicted inputs. As already mentioned in Section 2.2, the application of CFD methods to the EFM area involves many different sources of uncertainty. Uncertainty may be related to geometry and boundary conditions, drag coefficients, driving forces and the interactions among different and complex processes and inputs that could work on a very large range of spatial and temporal scales. A typical assumption could be to skip the effects of molecular diffusion on solute transport, since this process is negligible in natural fluid flows compared to turbulent diffusion. Finally, uncertainty arises from the treatment of turbulence, which is ubiquitous in natural fluid flows because of the large scales that these flows typically occupy and so it is an essential ingredient of EFM. This large degree of uncertainty often leads to simplifications of model geometry, the boundary conditions and inputs as well as to remove some processes that could be considered as negligible on the selected spatial and/or temporal scale. Again, this simplification occurs when using one of the above-mentioned approaches or levels of detail for simulating turbulent flow (Section 1). As already noted above, some simplifications were introduced in the study considering some of the remarks proposed by Knight et al. (2005) and Lane et al. (2005) for the specific case of open channel flows. Also, specific attention was given to the mesh resolution, considering and testing meshes with different characteristics and resolution. This led to four spatial zones with different spatial resolution modeling within the flow domain (Sections 3.2.3 and 3.4.2.).

\subsection{Model evaluation or testing (other models, algorithms, comparisons with alternatives)}

The final step is the evaluation of the model in the light of its objectives. Jakeman et al. (2006) noted that for simpler, disciplinary models the evaluation of a model corresponding to this step is traditionally termed validation, i.e. a comparison between model results and experimental data not used to build the model (Section 2.2). However, for larger, integrated models, the process of model evaluation should include a sensitivity analysis to changes in input parameters or, if possible, changes in model structure and a critical analysis about the process of model development, including the basic assumptions involved (Jakeman et al. 2006).

The first purpose of this study was to investigate the ability of a 2D RANS-based approach to reproduce the transverse turbulent mixing in a shallow flow. As the first step of model evaluation, a qualitative analysis of the concentration field for both geometries was carried out (Fig. 4). Second, eighteen locations downstream of the 
injection point were considered to derive the cross-section tracer concentration distribution (Fig. 5). Note that in Geometry A and B the plume reached the walls at $\mathrm{x}=17.50 \mathrm{~m}$ and $\mathrm{x}=15 \mathrm{~m}$, respectively.

For both Geometry A and Geometry B, concentration values were post-processed with different methods, such as the method of moments (where applicable), a method based on the transverse profile of turbulent viscosity $v_{t}$ and a method based on the analysis of the variance of the transverse concentration profile (where applicable), to derive $D_{t-y}$. Third, consistent with the validation issue of the model, the numerical results for $D_{t-y}$ in Geometry A were compared with the experimental data by Lau and Krishnappan (1977) in a rectangular flume. This comparison showed that numerical results tended to overestimate $\mathrm{D}_{\mathrm{t}-\mathrm{y}}$. In particular, the numerical value exceeded the maximum experimental value by about $30 \%$. This is not unexpected since as stated in Section 3.7, the assumption of isotropy can lead the k- $\varepsilon$ model to predict large turbulent viscosity and, consequently, high turbulent rates of mixing. Part of the first objective of the study was to identify the magnitude of this overestimation inherent to the hypothesis underlying the k- $\varepsilon$ model. On the other hand, also literaturebased predictive equations for $\mathrm{D}_{\mathrm{t}-\mathrm{y}}$ are affected by large uncertainties. So, if only bulk mixing properties are needed, RANS-modeling of transverse turbulent mixing appears to be an acceptable tool.

Furthermore, consistent with the second purpose of the study, numerical results demonstrated that the introduction of a grid upstream of the point of injection resulted in an enhanced mixing of the tracer and an increase of about $70 \%$ in $\mathrm{D}_{\mathrm{t}-\mathrm{y}}$. Note that the increase in the experimental works from Rummel et al. (2005) for three different grid geometries was larger, up to a factor 10 higher and more.

Finally, the study included a sensitivity analysis on some of the input parameters, such as the inlet turbulence intensity and length scale (Section 3.2.2) and the turbulent Schmidt number (Section 3.5). Numerical results pointed out the significant role of these parameters highlighting the need for their careful estimation in the numerical simulation of transverse turbulent mixing.

\section{Case study 2: natural ventilation of the Amsterdam ArenA football stadium}

A large part of this case study was previously published as a research paper in this journal [van Hooff T, Blocken B. 2010. Coupled urban wind flow and indoor natural ventilation modelling on a high-resolution grid: A case study for the Amsterdam ArenA football stadium. Environmental Modelling and Software 25(1), 51-65]. (van Hooff and Blocken 2010a). As in the previous case study, it is not the intention here to repeat all the details and results of the modeling study, but to explore the application of the ten-steps approach to this case study. Again, each of the sections below refers to one of the ten steps.

\subsection{Definition of the purposes for modeling}

The Amsterdam ArenA (Fig. 6a) is a multifunctional stadium situated in an urban area with multiple surrounding high-rise buildings (Fig. 6b). Apart from sports events, the stadium also hosts a wide variety of other activities, such as concerts and festivities. For this purpose, the stadium is equipped with a roof construction that can be opened and closed depending on the weather conditions and the type of event (Fig. 6c). For concerts, the roof is closed, and the equipment for light and sound is mounted below the roof (Fig. 6d). The roof consists of steel trusses covered with transparent polycarbonate sheets (Fig. 6c). The polycarbonate sheets allow the entrance of short-wave solar radiation, which is absorbed by the interior surfaces and emitted as long-wave radiation, which can not be transmitted through the polycarbonate sheets. This greenhouse effect increases the indoor air temperature. The concerts are held on several consecutive days during summer and throughout this period, the roof remains closed. In addition, the more than 50,000 spectators that are present during the concerts all emit considerable amounts of heat, water vapor and $\mathrm{CO}_{2}$. As a result, the indoor comfort and air quality can deteriorate. To ensure comfortable and healthy indoor conditions, many contemporary buildings are equipped with mechanical HVAC systems (Heating, Ventilation and Air-Conditioning). The application of such systems for closed or semi-enclosed stadia however is not straightforward, because of their very large interior volume. The interior volume of the ArenA stadium is $1.2 \times 10^{6} \mathrm{~m}^{3}$. In such cases, mechanical ventilation is difficult, expensive and not necessarily effective and efficient. Indeed, the Amsterdam ArenA is not equipped with HVAC systems, apart from smaller sub-systems such as local radiative gas heaters. In such cases, natural ventilation can be an important, sustainable and viable alternative to improve the indoor air quality. Natural ventilation refers to the exchange of outdoor and indoor air due to either wind or buoyancy, or both. Apart from these driving forces, natural ventilation requires the presence of sufficiently large ventilation openings between the outdoor and the indoor environment. Besides the roof, which is considered to be closed in this study, the ArenA has three types of openings (Fig. 7): (1) the four gates in the corners of the stadium (4 x $41.5 \mathrm{~m}^{2}$ ) (Fig. 7a,b); (2) the opening between the upper stand and the steel roof construction, which runs along the entire perimeter of the roof (total surface area of $130 \mathrm{~m}^{2}$ ) (Fig. 7d); and (3) the opening between the fixed and movable part of the roof, which is present along the two longest edges of the stadium (total surface area of $85 \mathrm{~m}^{2}$ ) (Fig. 7e). To analyze the indoor conditions and natural ventilation of the stadium with closed roof, full-scale measurements were made during 
summer 2007 of, among others, indoor and outdoor air temperature, irradiance of the sky and the air exchange rate $\left(\mathrm{ACH}\right.$ or Air Change rate per Hour) of the large indoor volume, based on the $\mathrm{CO}_{2}$ concentration decay method. The measurements indicated that the natural ventilation of the stadium was significant but insufficient during the concerts and also during other periods. They confirmed the need for a study to improve the natural ventilation of the stadium.

For this case study, a detailed CFD model was developed for coupled urban wind flow and indoor natural ventilation. This effort was driven by two modeling purposes related to two different stakeholders. The purposes of the model, in combination with field measurements, were:

- to investigate the ability of the model to reproduce the natural ventilation of the stadium driven by the combined effect of wind and buoyancy. More specifically, the question was how well CFD simulations would be able to reproduce the coupled urban wind flow and indoor natural ventilation of the stadium. The stakeholders of this purpose were the researchers in urban physics and the CFD modeling community;

- to evaluate the effectiveness of different alternative ventilation configurations with additional openings and/or increased opening sizes, to increase the natural ventilation. The related stakeholders were the stadium management. The model should provide guidance to the stadium management on how to add or modify the ventilation openings in order to enhance the natural ventilation, and to create a more comfortable and a healthier indoor environment.

These purposes or objectives of this case study can be broken down into the following general purposes mentioned by Jakeman et al. (2006): "Knowledge elicitation and review", "Prediction, both extrapolation from the past and "what if" exploration", "Interpolation: estimating variables which cannot be measured directly (state estimation)" and "Providing guidance for management and decision-making". Note that CFD was selected for this study for the three reasons by Robson et al. (2008) that were mentioned in Section 2.3.

\subsection{Specification of the modeling context: scope and resources}

\subsubsection{Specific issues and questions to be addressed by the model}

A specific issue to be addressed by the model is the coupled simulation of outdoor wind flow and indoor airflow on a high-resolution mesh. As explained in Murakami et al. (1991), Kato et al. (1997), Karava et al. (2011b), van Hooff and Blocken (2010a) and Ramponi and Blocken (2012), accurate modeling of natural ventilation through large openings requires a coupled approach, in which the outdoor wind flow and indoor airflow are solved simultaneously within the same computational domain and on the same computational mesh. This however implies inclusion of a wide range of length scales in a single domain and mesh, from $1 \mathrm{~km}$ (outdoor wind flow urban area) to a few centimeters (indoor air flow - smallest ventilation openings). In this situation, generating a high-resolution and high-quality computational mesh that satisfies the best practice guidelines is not straightforward and requires considerable effort. However, such a mesh is important to obtain accurate and reliable results. It should be noted that this coupled approach is important in case of large ventilation openings, because the decoupled approach, in which the outdoor wind flow and indoor air flow are solved in two separate computational domains, can introduce important errors. Indeed, the so-called "sealed-body assumption" in the decoupled approach implies that the pressure distribution on the building envelope is not affected by the presence of the openings (Murakami et al. 1991, Kato et al. 1997, Karava et al. 2007). It assumes that the turbulent kinetic energy is dissipated at the windward opening and that the effect of the dynamic pressure on the air flow passing through the opening is negligible (Etheridge and Sandberg 1996). However, Murakami et al. (1991), Kato et al. (1997), Sandberg (2004) and Karava et al. (2006, 2011) correctly pointed out that in case of wind flow through large ventilation openings, the turbulent kinetic energy is rather preserved and the sealedbody assumption is therefore not longer valid.

\subsubsection{Available resources}

Three sets of resources were available for this project: (1) detailed building plans; (2) a specific body-fitted mesh generation technique for complex high-resolution meshes in urban aerodynamics and (3) the commercial CFD solver and postprocessor Fluent 6.3 (Fluent Inc. 2006).

The detailed building plans were required to reproduce the 3D building geometry. In this case, the software Gambit 2.4 was used. CAD geometry files and GIS data files were also available. However, the CAD geometry files were too detailed and the GIS data files were insufficiently detailed. In addition, GIS data do not provide the geometry of the stadium interior.

In the original paper (van Hooff and Blocken 2010a), we developed a specific body-fitted mesh generation technique to efficiently and simultaneously generate the geometry and the high-resolution body-fitted mesh for both the outdoor and indoor environment. This technique allows modeling complex geometries with full control over mesh quality and mesh resolution, contrary to standard semi-automatic unstructured mesh generation 
techniques. It uses only hexahedral and prismatic cells, and avoids the use of tetrahedral and pyramid cells, which can have negative effects in terms of numerical diffusion and convergence with higher-order discretization schemes. The mesh generation technique also provides a way to easily implement various changes in the model geometry and mesh for parametric studies.

The commercial CFD code Fluent 6.3 was used. While also other codes could have been used, we chose Fluent 6.3 based on our successful application and validation of simulations with this code for a wide range of studies in EFM (e.g. Blocken et al. 2004, Blocken and Carmeliet 2002, 2006, 2007, 2008, Moonen et al. 2006, Blocken et al. 2007b, 2008a, 2008b, 2009, Blocken and Persoon 2009, Abuku et al. 2009, Defraeye et al. 2010, Gousseau et al. 2011a, 2011b). The simulations were performed using parallel processing on a Sun Fire X4150 server containing two Quad-Core Intel Xeon E5440 2.83 GHz processors and 16 GB Fully Buffered DDR2 memory. The steady-state simulations were terminated after 6000 iterations with a total duration of 48 hours, when additional iterations showed no further convergence. The scaled residuals (Fluent Inc., 2006) reached the following minimum values: $10^{-7}$ for $\mathrm{x}, \mathrm{y}$ and $\mathrm{z}$ momentum, $10^{-6}$ for $\mathrm{k}$ and $\varepsilon, 10^{-8}$ for energy and $10^{-5}$ for continuity.

\subsubsection{Required outputs}

The required outputs of the model are the values of the ACH for the present ventilation configuration and for different alternative ventilation configurations. The $\mathrm{ACH}$ is not a direct result of the model, but can be calculated based on the velocity vectors in the ventilation openings. It is defined as the ratio Q/V (ASHRAE 2005), where $\mathrm{Q}\left(\mathrm{m}^{3} / \mathrm{s}\right)$ is the volumetric airflow rate into the indoor volume $\mathrm{V}$. Based on the $\mathrm{ACH}$, the application of the model should yield a ranking of the different ventilation configurations in terms of ventilation performance.

\subsubsection{Spatial and temporal scope, scale and resolution}

The present study classifies as a study in microscale urban aerodynamics. The term microscale refers to horizontal length scales between 1 and $10 \mathrm{~km}$. In determining the spatial scales of the modeling effort, a maximum and a minimum scale have to be set. For the maximum scale, i.e. the size of the computational domain, the best practice guidelines by Franke et al. (2007) and Tominaga et al. (2008b) were employed, yielding a domain with dimensions length $\mathrm{x}$ width $\mathrm{x}$ height $=2900 \times 2900 \times 908.5 \mathrm{~m}^{3}$. The minimum spatial scale is determined by the size of the relevant ventilation openings, which is $0.02 \mathrm{~m}$ in this study. The resulting domain is shown in Fig. 8a. As mentioned earlier, this wide range in spatial scales imposes high demands on the quality and the resolution of the computational mesh. The resulting hybrid mesh has about $5.6 \times 10^{6}$ prismatic and hexahedral cells and is shown in Figs. 8b-d. Concerning the temporal scale/resolution, a distinction is made between three sets of simulations:

(1) SET 1: steady-state isothermal RANS simulations to validate the model for neutral atmospheric approach flow and strong wind conditions without buoyancy in and around the stadium;

(2) SET 2: transient/unsteady thermal RANS simulations to validate the model for neutral atmospheric wind conditions including buoyancy by heat, $\mathrm{CO}_{2}$ and water vapor during the concerts in the stadium; and

(3) SET 3: steady-state thermal RANS simulations to analyze the performance of alternative ventilation configurations, in which both wind-induced and buoyancy-induced ventilation play a role.

For the second set of simulations, a time step of $30 \mathrm{~s}$ was used. These simulations were started from the initial conditions at 0:00 a.m. (end of concert, maximum level of indoor $\mathrm{CO}_{2}$ and water vapor concentration) and continued until about 3:00 a.m., when the indoor temperature, $\mathrm{CO}_{2}$ and water vapor concentration had reached the level of the outdoor values.

\subsubsection{Model flexibility}

Model flexibility was considered very important in the case study. As the time required to generate the highresolution computational mesh with the aforementioned technique constitutes the largest part (85-90\%) of the time for the total modeling effort, flexibility in generating additional meshes for the mesh-sensitivity analysis and additional geometries and meshes for the evaluation of the alternative ventilation configurations, was essential. Generating the meshes for mesh-sensitivity analysis was easily performed by the initial implementation of parametric resolution parameters in the mesh, which could be changed to generate a finer and a coarser mesh. Furthermore, prior to the modeling study, the possible alternative ventilation configurations were discussed with the stadium management team and they were all implemented within the same computational "master mesh". Removing or adding additional ventilation openings in this mesh could then easily be done by either removing the associated mesh volumes or by meshing these volumes (in which meshing the openings means that they are open). For more details, the reader is referred to van Hooff and Blocken (2010a). 


\subsubsection{Users of the model}

Given the very large number of input parameters and the large sensitivity of the model results to the choices made by the user, the model should only be used and applied by CFD experts. The powerful and user-friendly graphical user interface of the Fluent 6.3 software does not change this point of view. Knowledge of urban aerodynamics, physical models, potential physical and numerical modeling errors and of the sensitivity of the model results to the input parameters is important for a correct application of the model and a correct interpretation of the model results. It should be noted that the indirect user community of the model results is much larger and includes the stadium management and all beneficiaries of improved indoor environmental conditions, such as the concert visitors.

\subsection{Conceptualization of the system, specification of data and other prior knowledge}

Conceptualization of the system refers to the processes that drive the natural ventilation, i.e. wind and buoyancy (Linden 1999, Hunt and Linden 1999, Li and Delsante 2001). In the case of the stadium and its microscale urban environment, the incoming (approach-flow) atmospheric boundary layer (ABL) brings air, water vapor, $\mathrm{CO}_{2}$ and heat to the urban area. The balance between mechanical turbulence generation (due to friction with the surface of the earth) and buoyancy related turbulence generation determines the vertical mean wind speed, turbulence, water vapor, $\mathrm{CO}_{2}$ and temperature profiles. Depending on the characteristics of these profiles, the $\mathrm{ABL}$ is called neutrally stratified, stably stratified or unstably stratified. The incoming wind flow is heated or cooled down due to surface convective heat transfer with the natural and urban surfaces and due to latent heat sources and sinks. Similarly, the vapor and $\mathrm{CO}_{2}$ concentration of the incoming wind flow are changed by surface convective mass transfer and due to sources and sinks. Inside the stadium, a multitude of material surfaces (mostly concrete and steel) are present, at which heat and mass transfer occur. As mentioned earlier, the roof, partly made of polycarbonate sheets, allows entrance of short-wave solar radiation but traps the emitted long-wave radiation, which increases the indoor air temperature. When the stadium is occupied, the more than 50,000 visitors are an important source of heat, water vapor and $\mathrm{CO}_{2}$ issued to the indoor air. The interaction of the outdoor urban wind flow with the indoor airflow through the ventilation openings adds to the complexity of this system. Figure 9 is a graphical representation of the conceptualization of the system.

Attempting to explicitly include all of these processes in detail in a model is neither feasible nor efficient. Which processes should be included and in which way depends on the modeling purposes, on the available information and on the importance of these processes. The very large range of possible meteorological conditions and possible stadium boundary conditions require a careful selection of only a limited set of these, to restrict the extent of the modeling effort.

As already pointed out in the first case study, prior knowledge on this system, as any system in EFM, includes at least conservation of mass, Newton's second law and conservation of energy.

\subsection{Selection of model features and families}

\subsubsection{Modeling approach}

In the past, a wide range of methods have been applied to analyze natural ventilation of buildings. Chen (2009) has provided a detailed overview of assessment methods for ventilation, which include analytical and/or semiempirical formulae (e.g. Linden 1999, Li and Delsante 2001) and numerical simulation with CFD (e.g. Tsutsumi et al. 1996, Jiang et al. 2003, Heiselberg et al. 2004, Norton et al. 2009, 2010, van Hooff and Blocken 2010a, 2010b). Analytical and semi-empirical formulae have generally been applied for simplified configurations and have proved very valuable to gain insight in the process of natural ventilation, such as the combined effects of wind and buoyancy as driving forces (e.g. Hunt and Linden 1999, Li and Delsante 2001). They are however less suitable for practical applications for specific buildings in specific environments. This is certainly the case for buildings and ventilation openings of complex geometry, as in this case study. For such applications, CFD is an interesting option (e.g. Chen 2009, Norton et al. 2009, 2010, van Hooff and Blocken 2010a, 2010b). In the past, both RANS and LES CFD modeling have been applied for natural ventilation studies.

For the present study, CFD is considered the best choice. The main reasons are (1) the complex geometry of the stadium and its ventilation openings; (2) the combined effect of wind flow and buoyancy forcing the natural ventilation; and (3) the crucial role of the detailed flow around and through the ventilation openings which governs the coupling between the urban wind flow and the resulting indoor natural ventilation. No other modeling method is available that can allow accurate assessment of the airflow rates through the complex ventilation openings. Additional advantages of CFD are that it can incorporate the effect of urban surroundings on the natural ventilation and that it provides whole-flow field data which allows determining the ACH. The main disadvantage of CFD in this study is the time-consuming effort to generate the high-resolution mesh. 
However, this effort was considered acceptable given the importance of the study and the fact that no alternatives were available. Indeed, reduced-scale wind tunnel modeling was not an option because scaling down the (small) ventilation openings would change the flow regime through these openings (from turbulent flow to transitional flow or even laminar flow), which would be an unacceptable violation of similarity requirements.

\subsubsection{Conceptual model}

As mentioned earlier, it is neither feasible nor efficient to include all physical processes involved and to encompass all possible combinations of meteorological conditions and stadium usage conditions. Instead, substantial simplifications were adopted and only the most relevant processes were included, based on knowledge of the scientific literature and on past experience in CFD modeling. A first set of simplifications was related to the model geometry, as explained in the next section 4.4.3. A second set of simplifications was related to the physical processes and the boundary conditions. Concerning the urban wind flow, a neutral ABL was modeled with constant temperature along the height of the domain. In line with the assumption of neutral atmospheric stratification, all building surfaces outside the stadium were modeled as adiabatic. Radiation and surface water vapor transfer outside the stadium were not included. Concerning the airflow inside the stadium, buoyancy is important here due to the low indoor air speed. For the thermal simulations, fixed temperatures were applied at all interior surfaces, which avoided the need to model radiative heat transfer inside the stadium and thermal storage in the stadium materials. The resulting simplified conceptual model is illustrated in Fig. 10.

\subsubsection{Spatial and temporal scales}

Note that the spatial and temporal scales were actually already mentioned in step 2 . Here and in the next section 4.5 , they are addressed in view of model simplifications and assumptions.

As mentioned before, the present study is a study in microscale urban aerodynamics. In modeling microscale urban aerodynamic processes, a distinction can be made in four spatial zones with different spatial resolution modeling: three zones inside the computational domain and one zone outside the computational domain; see Fig. 11.

(1) Zone 1: Only the stadium is modeled explicitly including geometrical details with high spatial resolution.

(2) Zone 2: The buildings and other terrain features further away from the stadium, the geometry of which is expected to have a direct influence on the flow around the stadium, are also modeled explicitly, but only with their main shape and dimensions. Details such as balconies are not represented, as the flow around these features is expected to have a negligible influence on the flow around the stadium.

(3) Zone 3: The buildings and terrain features at an even larger distance from the stadium, which are expected to have only an indirect influence on the flow around the stadium, are not modeled explicitly, but implicitly, i.e. by appropriately increased values of the equivalent sand-grain roughness height $\mathrm{k}_{\mathrm{S}}$ and the roughness constant $\mathrm{C}_{\mathrm{S}}$ in the wall functions applied to the bottom surface of the computational domain (Blocken et al. 2007a).

(4) Zone 4: Finally, the buildings and terrain features outside the computational domain are modeled implicitly by specifying appropriate boundary conditions (inlet profiles) at the inlet of the domain, based on the aerodynamic roughness length $\left(\mathrm{z}_{0}\right)$ of the upstream terrain.

\subsection{Determine how model structure and parameter values are to be found}

The variables of interest are the three components of the velocity vector, pressure, temperature, water vapor and $\mathrm{CO}_{2}$ concentration. From the velocity vectors in the ventilation openings, the ventilation flow rate and the $\mathrm{ACH}$ can be determined. The relations between the variables in the model are given by the physical laws of conservation of mass, Newton's second law and conservation of energy, which are prescribed by partial differential equations which can be simplified by e.g. Reynolds averaging (RANS approach) or filtering (LES approach). The selection of the turbulence model to close the RANS or LES equations is performed based on literature review and on past experience in modeling urban aerodynamics. The (default) turbulence model parameters (constants) have been based on extensive fitting to experimental data for a wide range of flow problems. The value of $\mathrm{Sc}_{\mathrm{t}}$ for water vapor and $\mathrm{CO}_{2}$ gas dispersion $\left(\mathrm{Sc}_{\mathrm{t}}=0.7\right)$ is based on previous studies reported in the literature. Buoyancy is modeled by the Boussinesq approximation. The inlet profiles, wall functions and wall function roughness modifications are extracted from the scientific literature: Richards and Hoxey (1993), Launder and Spalding (1974) and Cebeci and Bradshaw (1977), respectively. An important set of parameters are those in these inlet profiles $\left(\mathrm{z}_{0}\right)$ and wall functions $\left(\mathrm{k}_{\mathrm{S}}\right.$ and $\left.\mathrm{C}_{\mathrm{S}}\right)$. Accurate determination of these parameters is crucial for the accuracy of the modeling effort (e.g. Blocken et al. 2007a, 2007b). Determining the values of these parameters is different for each zone indicated in Fig. 11: 
(1) For zone 1, the parameter $\mathrm{k}_{\mathrm{S}, 1}$ is the small-scale equivalent sand-grain roughness of the building surfaces and the surrounding streets, and $\mathrm{C}_{\mathrm{S}, 1}$ is the roughness constant, mostly taken equal to 0.5 .

(2) For zone 2, $\mathrm{k}_{\mathrm{S}, 2}$ is the small-scale roughness of the building surfaces and streets. Because less of the detailed building and street geometry is explicitly modeled, $\mathrm{k}_{\mathrm{S}, 2}$ needs to be increased to compensate for this nonexplicitly modeled roughness. $\mathrm{C}_{\mathrm{S}, 2}$ is set equal to 0.5 .

(3) For zone $3, \mathrm{k}_{\mathrm{S}, 3}$ is the large-scale roughness that should represent the roughness of the non-explicitly modeled buildings. It is determined based on an estimate of the local $\mathrm{z}_{0,3}$ from the Davenport-Wieringa roughness classification (Wieringa 1992) and on the consistency relationship derived by Blocken et al. (2007a). For Fluent 6.3, this relationship is $\mathrm{k}_{\mathrm{S}, 3}=9.793 \mathrm{z}_{0,3} / \mathrm{C}_{\mathrm{S}, 3}$.

(4) For zone 4, the parameter $z_{0,4}$ in the inlet profiles is estimated from the Davenport-Wieringa roughness classification based on an upstream terrain distance (fetch) of 5-10 km.

Providing a good estimate for $\mathrm{k}_{\mathrm{S}, 2}$ and $\mathrm{C}_{\mathrm{S}, 2}$ is not straightforward. Earlier research (Blocken and Persoon 2009) indicated that the values of these parameters can have a very strong influence on the local wind velocity magnitude in zone 1 and zone 2 . Therefore, on-site wind speed measurements have been used to determine the values of these parameters by calibration of model results to measurements.

\subsection{Choice of performance criteria}

As mentioned by Robson et al. (2008), performance criteria for environmental models must reflect the overall aims and specific objectives of the modeling activity. The first model purpose was to investigate the ability of the model to reproduce the natural ventilation of the stadium driven by the combined effect of wind and buoyancy. The model could be assessed as performing well if it could reproduce the measured mean wind speed and mean wind direction in the four gates of the stadium and the measured $\mathrm{CO}_{2}$ concentration decay after the concerts, using realistic boundary conditions with a consistent set of parameters. The second model purpose was to evaluate the effectiveness of alternative ventilation configurations, intended to increase the natural ventilation. The minimum performance criterium in this case is the ability to predict which alternative configurations provide a higher $\mathrm{ACH}$, under a specific set of realistic boundary conditions with a consistent set of parameters. Similar to the study by Robson et al. (2008), additional criteria for the model were that the predicted spatial and temporal patterns of mean velocity, pressure, temperature, water vapor and $\mathrm{CO}_{2}$ concentration were plausible in the light of our physical understanding of the system, i.e. that the model reproduces the expected behavior of the natural ventilation by wind and buoyancy.

\subsection{Identification of model structure and parameters}

This step is generally an iterative process involving hypothesis testing of alternative model structures. While we did not go through an extensive iterative process for the case study of the stadium, we did perform such iterations in previous CFD studies of urban aerodynamics that included validation with experiments. The knowledge and expertise extracted from those studies, in combination with the available best practice guidelines for CFD, has provided the guidance for identifying appropriate models and model parameters.

As mentioned by Jakeman et al. (2006), the underlying aim of this step is "to balance sensitivity to system variables against complexity of representation". In this study, we selected the 3D RANS approach instead of the more time-consuming and more complicated LES or hybrid LES-URANS approach. We chose the realizable k- $\varepsilon$ turbulence model (Shih et al. 1995) to provide closure, because of its general good performance for wind flow around buildings (Franke et al. 2004, Blocken et al. 2008b, Blocken and Persoon 2009) and the overall good performance of k- $\varepsilon$ models for indoor air flow (Linden 1999, Sorensen and Nielsen 2003). The Boussinesq approximation was used for buoyancy. Radiation inside the stadium did not need to be taken into account because fixed temperatures were imposed on all surfaces inside the stadium. Pressure-velocity coupling was taken care of by the SIMPLE algorithm (Patankar and Spalding 1972), pressure interpolation was standard and second-order discretization schemes were used for both the convection and the viscous terms of the governing equations. For near-wall modeling, the standard wall functions by Launder and Spalding (1974) were used with the sand-grain based roughness modification by Cebeci and Bradshaw (1977). The parameters $\mathrm{z}_{0}, \mathrm{k}_{\mathrm{S}}$ and $\mathrm{C}_{\mathrm{S}}$ were determined as mentioned in Section 4.5.

\subsection{Conditional verification including diagnostic checking}

A distinction is made between quantitative and qualitative verification. Mesh-sensitivity analysis and comparison with measured data can be categorized as quantitative verification, but will be addressed in sections 4.9 and 4.10, respectively. In addition, two types of qualitative verification were performed, which were admittedly - rather informal actions. First, the model results were presented to scientists who were not CFD modelers, who confirmed the feasibility of the calculated wind flow and indoor airflow, and the calculated 
temperatures. They also confirmed the ranking of alternative ventilation configurations, which was a result of set 3 of the simulations. Second, the model results were presented to the stadium management team, who were neither CFD modelers, nor scientists. They confirmed the feasibility of the predicted increase in indoor temperature both during concerts and the credibility of the ranking of possible solutions.

\subsection{Quantification of uncertainty}

Uncertainty in CFD modeling for EFM can arise from a very wide range of sources, which makes a complete uncertainty analysis a nearly impossible task. Example sources are the simplification of model geometry, the mesh resolution, the choice of RANS versus LES, boundary conditions, etc. It should be noted that substantial reduction in uncertainty is achieved by carefully adhering to the CFD best practice guidelines. Indeed, as mentioned earlier, the main aim of these guidelines is to reduce as much as possible errors and uncertainty in CFD simulations. In the present study, these guidelines were carefully applied concerning the size of the computational domain, the extent of zone 2 with explicitly modeled buildings, the choice of steady RANS and the turbulence model, the choice of parameters $\mathrm{k}_{\mathrm{S}, 3}, \mathrm{C}_{\mathrm{S}, 3}$, and $\mathrm{z}_{0,4}$, the choice of discretization schemes, etc. In addition, nearly mesh independence of the results ( $2 \%$ deviation in gate flow rates) was ensured by a meshsensitivity analysis based on three different meshes. Important remaining uncertainties in the study are the simplifications of the thermal processes, especially inside the stadium. Imposing fixed surface temperatures is a rather strong simplification. However, including radiative heat transfer and thermal storage in the simulations would strongly increase complexity and computational cost. This was considered unnecessary to rank the alternative ventilation configurations, but could have contributed to a better match between the simulation results and the measured data.

\subsection{Model evaluation or testing (other models, algorithms, comparisons with alternatives)}

For this case study, we adopt the wider interpretation of model evaluation provided by Robson et al. (2008). They stated that a complete model evaluation goes beyond simply testing its efficacy in reproducing field conditions and should address the question of how useful the model is and how well it fulfils the purpose for which it was developed. They suggested different questions to be considered, which are addressed below.

(1) How well does the model reproduce an independent data set? The CFD simulations in set 1 were compared with wind speed measurements to determine the roughness parameters $\mathrm{k}_{\mathrm{S}, 2}$ and $\mathrm{C}_{\mathrm{S}, 2}$. This is calibration and not model evaluation or testing. One of the available independent data sets consisted of the wind velocity measurements in the four gates, which compared favorably with the simulations (see Fig. 12).

(2) How well does the model perform under unusual conditions? An additional test concerned model performance under unusual conditions, i.e. conditions that are substantially different from those for which the model was initially calibrated and applied. A rather specific condition occurred at the end of the concerts, when the indoor air temperature, water vapor and $\mathrm{CO}_{2}$ concentration had reached a maximum due to the visitors. When the visitors leave the stadium, the natural ventilation will cause the indoor temperature, water vapor and $\mathrm{CO}_{2}$ concentration to gradually decrease towards the outdoor values. The second set of simulations mentioned in section 4.7 consisted of modeling this effect. Comparing the model results with the corresponding measurements showed that the model could indeed accurately reproduce the gradual decrease of indoor air temperature, water vapor and $\mathrm{CO}_{2}$ concentration. As an example, Fig. 13 illustrates contours of $\mathrm{CO}_{2}$ concentration in a vertical cross-section through the stadium, at six different positions in time following the end of a concert. The figure clearly shows the gradual decrease of the concentration with time.

(3) Is the complex model better than a simpler one? Considerable simplifications were adopted, as explained in section 4.4.2. Nevertheless, this simplified model accurately reproduced different sets of independent measurement data. Further simplification of the model could consist of decoupling outdoor wind flow and indoor airflow, and/or simplification of the stadium geometry. Both options were considered unsuitable for this study. Decoupling outdoor and indoor flow would require the knowledge of pressure coefficients, which were not available and would require detailed CFD simulations or wind tunnel tests themselves. Simplification of the stadium geometry would not allow assessing the impact of the detailed geometry of the ventilation openings, which was one of the main purposes of this study.

(4) Can the model be used to improve understanding of underlying system function and finally, and most importantly, does the model help to answer questions about the system function and can it be used to make predictions about the future? Because the model accurately reproduced the combined action of wind and buoyancy on natural ventilation in the first and second set of simulations, it was used to increase understanding of the interaction between the two driving forces and to predict the performance of the different ventilation configurations. These different configurations were evaluated in the third set of simulations. They consisted of some specific small additional openings in the stadium envelope and of increased ventilation openings near the 
roof. It was shown that the former measure did not substantially improve the ventilation performance, but that the latter measure increased the ACH by up to $43 \%$.

\section{Summary and conclusions}

Computational Fluid Dynamics (CFD) methods are increasingly used to study a wide variety of complex Environmental Fluid Mechanics (EFM) processes, such as turbulent flow and mixing of contaminants in rivers, lakes and estuaries and wind flow and air pollution dispersion in urban areas. However, the accuracy and reliability of CFD modeling and the correct use of CFD results can easily be compromised. In 2006, Jakeman et al. set out ten iterative steps of good disciplined model practice to develop purposeful, credible models from data and a priori knowledge, in consort with end-users, with every stage open to critical review and revision. The present paper has discussed the application of the ten-steps approach to CFD for EFM in three parts.

In the first part, the existing best practice guidelines for CFD applications in this area have been reviewed in the light of the ten-steps approach. The existing best practice guidelines in CFD are mainly focused on verification, validation and sensitivity analysis, which largely corresponds to the last three steps in the ten-steps approach. Two main reasons are responsible for this. The first reason is the generic character of the ten-steps approach versus the more specific character of CFD. Actually, the choice to use CFD as a modeling approach is a possible outcome of step 4 of the ten-steps approach (selection of model features and families). Indeed, other and more simplified modeling approaches exist for EFM, although in many cases there is a clear preference in the EFM community for CFD, given the specific advantages of this type of process-based models. The choice for CFD in the EFM field should actually be the result of the execution of steps 1 to 4 and to some extent of steps 5 and 7. Note that in CFD the choice of a model family needs further decisions about the model structure and model parameters within a large range of possibilities considering the different physical processes to be modeled. However, in EFM studies the risk also exists that steps 1 to 3 are overlooked or are given insufficient attention and that CFD is selected while less complex models could suffice. The second reason is the specific disadvantages of process-based models such as CFD. As specified by Robson et al. (2008), these models generally have high data input requirements, a high level of complexity and high computational costs, which impose a strong need for verification, validation and uncertainty analysis. It is therefore not surprising that the existing best practice guidelines for CFD have focused mainly on exactly these three actions, which indeed correspond mainly to the last three steps in the ten-steps approach. It is advisable that future best practice guidelines for CFD applications in the EFM field will include a larger application of benchmarking because it provides relevant information for reliable comparisons among different CFD techniques and approaches. So specific benchmarks should be developed in the different contexts and practical applications of CFD methods to EFM.

The second and third parts of this paper have presented a retrospective analysis of two EFM case studies in the light of the ten-steps approach. The first case study was transverse turbulent mixing in a shallow water flow (Gualtieri 2010). It demonstrated the ability of a 2D RANS-based approach to reproduce the transverse turbulent mixing if only bulk mixing properties are needed. It also allowed to investigate the effect of a grid of square components located upstream of the point of injection on transverse turbulent mixing. The second case study was coupled urban wind flow and indoor natural ventilation of the Amsterdam ArenA football stadium (van Hooff and Blocken 2010a). It successfully indicated the ability of 3D RANS modeling to reproduce the natural ventilation of the stadium by the combined effect of wind and buoyancy. It was also used to evaluate the effectiveness of different alternative ventilation configurations resulting in enhanced natural ventilation and a more comfortable and healthier indoor environment. Note that the two case studies were selected because of their large differences: water versus air as bulk fluid, two-dimensional (2D) versus three-dimensional (3D) modeling, finite-element versus control-volume technique and different turbulence models. The intention of the retrospective analysis was twofold. First, to illustrate that high-quality and extensive EFM studies with CFD should - implicitly or explicitly - during their execution have addressed each of the ten steps. Second, to illustrate that the ten-steps approach is very suitable in developing and executing EFM studies with CFD. One might argue that, for the specific purpose of CFD modeling, there is some overlap between some steps, such as steps 8, 9 and 10, but this does not pose any problem and is considered inherent to the generic character of the ten-steps approach. The two case studies and their large differences serve to illustrate the wide applicability of the ten-steps approach for CFD in EFM.

In conclusion, this paper has shown that the ten-steps approach can be properly applied to CFD studies for EFM and that it provides a comprehensive framework that encompasses and extends the existing best practice guidelines. It is therefore suggested that future CFD studies in the EFM realm more explicitly address and document all steps in the ten-steps approach, as part of the continuing efforts towards more purposeful, credible models based on critical review and revision. 


\section{Acknowledgements}

The authors thank the anonymous reviewers for thoroughly reading the manuscript and for their valuable comments.

\section{References}

Abuku, M., Blocken, B., Nore, K., Thue, J.V., Carmeliet, J. and Roels, S., 2009. On the validity of numerical winddriven rain simulation on a rectangular low-rise building under various oblique winds. Build. Environ., 44 (3), 621-632.

AIAA, 1998. Guide for the verification and validation of computational fluid dynamics simulations, American Institute of Aeronautics and Astronautics, AIAA, AIAA-G-077-1998, Reston, VA.

Ahmad, Z., 2008. Finite volume model for steady-state transverse mixing in streams, J. Hydraul. Res. 46(1), 72-80.

ASHRAE, 2005. Handbook of Fundamentals. American Society of Heating, Refrigerating and Air-Conditioning Engineers, Inc., Atlanta, USA.

ASME, 1993. Journal of Fluids Engineering Editorial Policy Statement on the Control of Numerical Accuracy. J. Fluid Eng.-T. ASME 115(9), 339-340.

ASME, 2009. Standard for verification and validation in Computational Fluid Dynamics and heat transfer. ASME V\&V 20-2009, The American Society of Mechanical Engineers.

Baetke, F., Werner, H. and Wengle, H., 1990. Numerical simulation of turbulent flow over surface-mounted obstacles with sharp edges and corners. J. Wind Eng. Ind. Aerodyn. 35 (1-3), 129-147.

Balczo, M., Gromke, C., Ruck, B., 2009. Numerical modeling of flow and pollutant dispersion in street canyons with tree planting. Meteorol. Z. 18(2), 197-206.

Bartzis, J.G., Vlachogiannis, D., Sfetsos, A., 2004. Thematic area 5: Best practice advice for environmental flows. The QNET-CFD Network Newsletter 2(4), 34-39.

Bates, P.D., Lane, S.N., Ferguson, R.I., (Eds), 2005. Computational Fluid Dynamics. Applications in environmental hydraulics, John Wiley \& Sons, Chichester, England, pp.534, (ISBN 978-0-470-84359-8)

Bayani-Cardenas, M., Wilson, J.L., 2007a. Hydrodynamics of coupled flow above and below a sediment-water interface with triangular bedforms. Adv. Water Resour. 30(1), 301-313.

Bayani-Cardenas, M., Wilson, J.L., 2007b. Dunes, turbulent eddies, and interfacial exchange with permeable sediments, Water Resour. Res. 45(3), W08412.

Bayani-Cardenas, M., Wilson, J.L., Haggerty, R., 2008. Residence time of bedform-driven hyporheic exchange. Adv. Water Resour. 31, 1382-1386.

Bayani-Cardenas, M., 2009. A model for lateral hyporheic flow based on valley slope and channel sinuosity. Water Resour. Res. 45, W01501

Blocken, B., Carmeliet, J., 2002. Spatial and temporal distribution of driving rain on a low-rise building. Wind Struct. 5(5), 441-462.

Blocken, B., Carmeliet, J., 2004. A review of wind-driven rain research in building science. J. Wind Eng. Ind. Aerodyn. 92(13), 1079-1130.

Blocken, B., Roels, S., Carmeliet, J., 2004. Modification of pedestrian wind comfort in the Silvertop Tower passages by an automatic control system. J. Wind Eng. Ind. Aerodyn. 92 (10), 849-873.

Blocken, B., Carmeliet, J., 2006. The influence of the wind-blocking effect by a building on its wind-driven rain exposure. J. Wind Eng. Ind. Aerodyn. 94(2), 101-127.

Blocken, B, Carmeliet, J., 2007. Validation of CFD simulations of wind-driven rain on a low-rise building facade. Build. Environ. 42 (7), 2530-2548.

Blocken, B., Stathopoulos, T., Carmeliet, J., 2007a. CFD simulation of the atmospheric boundary layer: wall function problems. Atmos. Environ. 41(2), 238-252.

Blocken, B., Carmeliet, J., Stathopoulos, T., 2007b. CFD evaluation of wind speed conditions in passages between parallel buildings - effect of wall-function roughness modifications for the atmospheric boundary layer flow. J. Wind Eng. Ind. Aerodyn. 95 (9-11), 941-962.

Blocken, B., Stathopoulos, T., Saathoff, P., Wang, X., 2008a. Numerical evaluation of pollutant dispersion in the built environment: comparisons between models and experiments. J. Wind Eng. Ind. Aerodyn. 96(10-11), 1817-1831.

Blocken, B., Stathopoulos, T., Carmeliet, J., 2008b. A numerical study on the existence of the Venturi-effect in passages between perpendicular buildings. J. Eng. Mech.-ASCE 134(12), 1021-1028.

Blocken, B., Carmeliet, J., 2008. Pedestrian wind conditions at outdoor platforms in a high-rise apartment building: generic sub-configuration validation, wind comfort assessment and uncertainty issues. Wind Struct. 11(1), 5170.

Blocken, B., Persoon, J., 2009. Pedestrian wind comfort around a large football stadium in an urban environment: CFD simulation, validation and application of the new Dutch wind nuisance standard. J. Wind Eng. Ind. Aerodyn. 97(5-6), 255-270. 
Blocken, B., Defraeye, T., Derome, D., Carmeliet, J., 2009. High-resolution CFD simulations for convective heat transfer coefficients at the facade of a low-rise building. Build. Environ. 44 (12), 2396-2412.

Blocken, B., Carmeliet, J., 2010. Overview of three state-of-the-art wind-driven rain assessment models and comparison based on model theory. Build. Environ. 45 (3), 691-703.

Blocken, B., Deszö, G., van Beeck, J., Carmeliet, J., 2010. Comparison of calculation methods for wind-driven rain deposition on building facades. Atmos. Environ. 44(14), 1714-1725.

Blocken, B., van Hooff, T., Aanen, L., Bronsema, B., 2011. Computational analysis of the performance of a venturi-shaped roof for natural ventilation: venturi-effect versus wind-blocking effect. Comput. Fluids 48(1), 202-213.

Blocken B, Janssen WD, van Hooff T. 2012. CFD simulation for pedestrian wind comfort and wind safety in urban areas: General decision framework and case study for the Eindhoven University campus. Environ. Modell. Softw. 30: 15-34.

Boxall, J.B., Guymer I., 2003. Analysis and prediction of transverse mixing coefficients in natural channels. J. Hydraul. Eng.-ASCE 129(2), 129-139.

Briggen, P.M., Blocken, B., Schellen, H.L., 2009. Wind-driven rain on the facade of a monumental tower: numerical simulation, full-scale validation and sensitivity analysis. Build. Environ. 44(8), 1675-1690.

Britter, R., Schatzmann, M. (Eds.), 2007. Model evaluation guidance and protocol document COST Action 732 , COST Office Brussels, ISBN: 3-00-018312-4.

Canepa, E., 2004. An overview about the study of downwash effects on dispersion of airborne pollutants. Environ. Modell. Softw. 19(12), 1077-1087.

Casey, M., Wintergerste, T., 2000. Best Practice Guidelines, ERCOFTAC Special Interest Group on Quality and Trust in Industrial CFD, ERCOFTAC, Brussels.

Cebeci, T., Bradshaw, P., 1977. Momentum transfer in boundary layers, Hemisphere Publishing Corporation.

Chen, Q., 2009. Ventilation performance prediction for buildings: A method overview and recent applications. Build. Environ. 44(4),: 848-858.

Choi, E.C.C., 1993. Simulation of wind-driven rain around a building. J. Wind Eng. Ind. Aerodyn. 46\&47, 721729.

Chu, A.K.M., Kwok, R.C.W., Yu, K.N., 2005. Study of pollution dispersion in urban areas using Computational Fluid Dynamics (CFD) and Geographic Information System (GIS). Environ. Modell. Softw. 20(3), 273-277.

Comsol Multiphysics 3.4 User's Guide, ComSol AB. Sweden, 2008

Cook, M.J., Zitzmann, T., Pfrommer, P., 2008. Dynamic thermal building analysis with CFD - modelling radiation. J. Build. Performance Simulation 1(2), 117-131.

Cowan, I.R., Castro, I.P., Robins, A.G., 1997. Numerical considerations for simulations of flow and dispersion around buildings. J. Wind Eng. Ind. Aerodyn. 67 \& 68, 535-545.

Cushman-Roisin, B, Gualtieri, C., Mihailović, D.T., 2008. Environ. Fluid Mech.: Current issues and future outlook, in: Gualtieri, C. and Mihailović, D.T., (Eds.), Fluid mechanics of environmental interfaces, Taylor \& Francis Ltd, London, 1-13.

Czernuszenko, W., Rowinski, P. (Eds), 2005. Water Quality Hazards and Dispersion of Pollutants", Springer Science+Business Inc., New York, NY, USA, pp.250, (ISBN 0-387-23321-0)

Defraeye, T., Blocken, B., Carmeliet, J., 2010. CFD analysis of convective heat transfer at the surfaces of a cube immersed in a turbulent boundary layer. Int. J. Heat Mass Tran. 53(1-3), 297-308.

Defraeye, T., Blocken, B., Carmeliet, J., 2011a. Convective heat transfer coefficients for exterior building surfaces: Existing correlations and CFD modelling. Energ. Convers. Manage. 52(1), 512-522.

Defraeye, T., Blocken, B., Carmeliet, J., 2011b. An adjusted temperature wall function for turbulent forced convective heat transfer for bluff bodies in the atmospheric boundary layer. Build. Environ. 46(11), 2130-2141.

Defraeye, T., Carmeliet, J., 2010. A methodology to assess the influence of local wind conditions and building orientation on the convective heat transfer at building surfaces. Environ. Modell. Softw. 25(12), 1813-1824.

Duan, J.G, 2004. Simulation of flow and mass dispersion in meandering channels. J. Hydraul. Eng.-ASCE, 130 (10), 964-976.

Dufresne, M., Vazquez, J., Terfous, A., Ghenaim, A., Poulet, J.B., 2009. CFD modeling of solid separation in three combined sewer overflow chambers. J. Environ. Eng.-ASCE 135(9), 776-787.

Endreny, T., Lautz, L., Siegel, D. I., 2011. Hyporheic flow path response to hydraulic jumps at river steps: Flume and hydrodynamic models. Water Resour. Res. 47, W02517.

Etheridge, D.W., Sandberg, M., 1996. Building ventilation: theory and measurement. Chichester, New York: John Wiley \& Sons.

Etyemezian, V., Davidson, C.I., Zufall, M., Dai, W., Finger, S., Striegel, M., 2000. Impingement of rain drops on a tall building. Atmos. Environ. 34(15), 2399-2412.

Fluent Inc., 2006. Fluent 6.3 User's Guide. Fluent Inc., Lebanon.

Franke, J., Hirsch, C., Jensen, A.G., Krüs, H.W., Schatzmann, M., Westbury, P.S., Miles, S.D., Wisse, J.A., Wright, N.G. 2004. Recommendations on the use of CFD in wind engineering. Proc. Int. Conf. Urban Wind 
Engineering and Building Aerodynamics, (Ed. van Beeck JPAJ), COST Action C14, Impact of Wind and Storm on City Life Built Environment, von Karman Institute, Sint-Genesius-Rode, Belgium, 5 - 7 May 2004.

Franke, J., Hellsten, A., Schlünzen, H., Carissimo, B., 2007. Best practice guideline for the CFD simulation of flows in the urban environment. COST 732: Quality Assurance and Improvement of Microscale Meteorological Models. COST Office Brussels, ISBN 3-00-018312-4.

Gorlé, C., van Beeck, J., Rambaud, P., Van Tendeloo, G., 2009. CFD modelling of small particle dispersion: the influence of the turbulence kinetic energy in the atmospheric boundary layer. Atmos. Environ. 43(3), 673-681.

Gousseau P, Blocken, B., Stathopoulos, T., van Heijst G.J.F., 2011a. CFD simulation of near-field pollutant dispersion on a high-resolution grid: a case study by LES and RANS for a building group in downtown Montreal. Atmos. Environ. 45(2), 428-438.

Gousseau P, Blocken, B., van Heijst G.J.F., 2011b. CFD simulation of pollutant dispersion around isolated buildings: On the role of convective and turbulent mass fluxes in the prediction accuracy. J. Hazard. Mater. 194, 422-434.

Gromke, C., Buccolieri, R., Di Sabatino, S., Ruck, B., 2008. Dispersion study in a street canyon with tree planting by means of wind tunnel and numerical investigations - Evaluation of CFD data with experimental data. Atmos. Environ. 42(37), 8640-8650.

Gualtieri, C., 2005. Numerical simulations of laminar backward-facing step flow with FemLab 3.1. ASME Fluids Engineering Summer Conference (FEDSM2005), Houston, (USA), July 19/23.

Gualtieri, C., 2006. Numerical simulations of flow and tracer transport in a disinfection contact tank. Proceedings of the iEMSs Third Biennial Meeting: International Congress on Environ. Modell. Softw. (iEMSs 2006), Burlington (USA), July 9/12 (ISBN 1-4243-0852-6)

Gualtieri C., Mucherino, C., 2007. Transverse turbulent diffusion in straight rectangular channels, $5^{\text {th }}$ International Symposium on Environmental Hydraulics (ISEH 2007), Tempe (USA), December 4-7.

Gualtieri C., Mucherino, C., 2008. Discussion on Tae Myoung Jeon, Kyong Oh Baek and Il Won Seo: Development of an empirical equation for the transverse dispersion coefficient in natural streams. Environ. Fluid Mech., 7 (4), 317-329, Environ. Fluid Mech., 8 (1), 97-100.

Gualtieri, C., 2009. Analysis of flow and concentration fields in a baffled circular storage tank. XXXIII IAHR Congress, Vancouver (Canada), August 10/14, 4384-4392 (ISBN 978-94-90365-01-1)

Gualtieri, C., López Jiménez, P.A., Mora-Rodriguez, 2010. Modelling turbulence and solute transport in a square dead zone. $1^{\text {st }}$ European IAHR Congress, Edinburgh (Gran Bretagna), May 4/6.

Gualtieri C., 2010. RANS-based simulation of transverse turbulent mixing in a 2D geometry. Environ. Fluid Mech. 10 (1-2), 137-156.

Hague, J., Ta, C.T., Biggs, M.J., Sattary, J.A., 2001. Small scale model for CFD validation in DAF application. Water Sci. Technol. 43 (8), 167-173

Hall, R.C. (Ed.), 1997. Evaluation of modelling uncertainty. CFD modelling of near-field atmospheric dispersion. Project EMU final report, European Commission Directorate-General XII Science, Research and Development Contract EV5V-CT94- 0531, WS Atkins Consultants Ltd., Surrey.

Hanjalić, K., 2004. Closure models for incompressible turbulent flows. Lecture Notes at Von Kármán Institute, pp.75

Hanna, S.R., Brown, M.J., Camelli, F.E., Chan, S.T., Coirier, W.J., Hansen, O.R., Huber, A.H., Kim, S., Reynolds, R.M., 2006. Detailed simulations of atmospheric flow and dispersion in downtown Manhattan. An application of five computational fluid dynamics models. Bulletin of the American Meteorological Society 87, 1713-1726.

Hargreaves, D.M., Wright, N.G., 2007. On the use of the $\mathrm{k}-\varepsilon$ model in commercial CFD software to model the neutral atmospheric boundary layer. J. Wind Eng. Ind. Aerodyn. 95(5), 355-369.

Heiselberg, P., Li, Y., Andersen, A., Bjerre, M., Chen, Z., 2004. Experimental and CFD evidence of multiple solutions in a naturally ventilated building. Indoor Air 14(1), 43-54.

Henderson F.M., 1966. Open channel flow, Macmillan Series in Civil Engineering, New York, NY, USA, pp.522.

Hensen, J.L.M., Lamberts, R., 2010. Building Performance Simulation for Design and Operation, Routledge, London.

Huang, S.H., Li, Q.S., 2010. Numerical simulations of wind-driven rain on building envelopes based on Eulerian multiphase model. J. Wind Eng. Ind. Aerodyn. 98(12), 843-857.

Hunt, G.R., Linden, P.F., 1999. The fluid mechanics of natural ventilation - displacement ventilation by buoyancydriven flows assisted by wind. Build. Environ. 34(6), 707-720.

Hussein A.S., El-Shishiny, H. 2009. Influences of wind flow over heritage sites: A case study of the wind environment over the Giza Plateau in Egypt, Environ. Modell. Softw. 24(3), 389-410.

Jakeman, A.J., Letcher, R.A., Norton, J.P., 2006. Ten iterative steps in development and evaluation of environmental models. Environ. Modell. Softw. 21(5), 602-614.

Jiang, Y., Chen, Q., 2002. Effect of fluctuating wind direction on cross natural ventilation in buildings from large eddy simulation. Build. Environ. 37 (4), 379-386. 
Jiang, Y., Alexander, D., Jenkins, H., Arthur, R., Chen, Q., 2003. Natural ventilation in buildings: measurement in a wind tunnel and numerical simulation with large-eddy simulation. J. Wind Eng. Ind. Aerodyn. 91(3), 331-353.

Jin, G., Tang, H., Gibbes, B., Li. L., Barry, D.A., 2010. Transport of nonsorbing solutes in a streambed with periodic bedforms, Adv. Water Resour. 33, 1402-1416.

Jirka, G.H., 2001. Large scale flow structures and mixing processes in shallow flows. J. Hydraul. Res. 39(6), 567573.

Jones, W.P., Launder, B.E., 1972. The prediction of laminarization with a 2-equation model of turbulence. Int. J. Heat Mass Tran. 15, 301.

Karama, A.B., Onyejekwe, O.O., Brouckaert, C.J., Buckley, C.A., 1999. The use of Computational Fluid Dynamics (CFD) technique for evaluatiing the efficiency of an activated sludge reactor. Water Sci. Technol. 39(10-11), 329-332

Karava, P., Stathopoulos, T., Athienitis, A.K., 2006. Impact of internal pressure coefficients on wind-driven ventilation analysis. Int J. Vent. 5, 53-66.

Karava, P., Stathopoulos, T., Athienitis, A.K., 2007. Wind-induced natural ventilation analysis. Sol. Energy 81, 20-30.

Karava, P., Jubayer, C.M., Savory, E., 2011a. Numerical modelling of forced convective heat transfer from the inclined windward roof of an isolated low-rise building with application to Photovoltaic/Thermal systems. Appl. Therm. Eng. 31(11-12): 1950-1963.

Karava, P., Stathopoulos, T., Athienitis, A.K., 2011b. Airflow assessment in cross-ventilated buildings with operable façade elements. Build. Environ. 46, 266-279.

Kato, S., Murakami, S., Takahashi, T., Gyobu, T., 1997. Chained analysis of wind tunnel test and CFD on cross ventilation of large-scale market building. J. Wind Eng. Ind. Aerodyn. 67-68, 573-587.

Khan, L.A., Wicklein, E.A., Texeira, E.C., 2006. Validation of a three-dimensional computational fluid dynamics model of a contact tank. J. Hydraul. Eng.-ASCE 132 (7), 741-746.

Knight, D.W., Wright, N.G., Morvan, H.P., 2005. Guidelines for applying commercial CFD software to open channel flow. Report based on research work conducted under EPSRC Grants GR/R43716/01 and GR/R43723/01, pp.31.

Lane, S.N., Hardy, R.J., Ferguson, R.I., Parsons, D.R., 2005. A framework for model verification and validation of CFD schemes in natural open channel flows, in Bates, P.D., Lane, S.N., and Ferguson, R.I., (Eds), Computational Fluid Dynamics. Applications in Environmental Hydraulics, John Wiley \& Sons, Chichester, England, pp.534, (ISBN 978-0-470-84359-8).

Lau, Y.L., Krishnappan, B.G., 1977. Transverse dispersion in rectangular channel. J. Hydr. Eng. Div.-ASCE 103, HY10, 1173-1189.

Launder, B.E., Spalding, D.B., 1974. The numerical computation of turbulent flows. Comput. Method. Appl. M. 3, 269-289.

Leitl, B.M., Kastner-Klein, P., Rau, M., Meroney, R.N., 1997. Concentration and flow distributions in the vicinity of U-shaped buildings: wind-tunnel and computational data. J. Wind Eng. Ind. Aerodyn. 67\&68: 745-755.

Li Y.G, Delsante, A. 2001. Natural ventilation induced by combined wind and thermal forces. Build. Environ. 36(1), 59-71.

Linden, P.F., 1999. The fluid mechanics of natural ventilation. Annu. Rev. Fluid Mech. 31, 201-238.

Liu, J., Crapper, M., McConnachie, G.L., 2004. An accurate approach to the design of channel hydraulic Flocculators. Water Res. 38, 875-886.

Menter, F.R., 1994. Two-equation eddy-viscosity turbulence models for engineering applications. AIAA J. 32 , 1598-1605.

Menter, F., Hemstrom, B., Henrikkson, M., Karlsson, R., Latrobe, A., Martin, A., Muhlbauer, P., Scheuerer, M., Smith, B., Takacs, T., Willemsen, S., 2002. CFD Best practice guidelines for CFD code validation for reactorsafety applications. Report EVOLECORA-D01, Contract No. FIKS-CT-2001-00154, 2002.

Meroney, R.N., 2004. Wind tunnel and numerical simulation of pollution dispersion: a hybrid approach. Working paper, Croucher Advanced Study Institute on Wind Tunnel Modeling, Hong Kong University of Science and Technology, 6-10 December, 2004, pp. 60.

Meroney, R.N., Leitl, B.M., Rafailidis, S., Schatzmann, M., 1999. Wind-tunnel and numerical modeling of flow and dispersion about several building shapes. J. Wind Eng. Ind. Aerodyn. 81, 333-345.

Milashuk, S., Crane, W.A., 2011. Wind speed prediction accuracy and expected errors of RANS equations in low relief inland terrain for wind resource assessment purposes. Environ. Modell. Softw. 26(4): 429-433.

Mochida, A., Lun, I.Y.F., 2008. Prediction of wind environment and thermal comfort at pedestrian level in urban area. J. Wind Eng. Ind. Aerodyn. 96 (10-11), 1498-1527.

Moiunuddin, K.A.M., Joubert, P.N., Chong, M.S., 2004. Experimental investigation of turbulence-driven secondary motion over a streamwise external corner. J. Fluid Mech. 511, 1-23.

Moinuddin, K.A.M., Ooi, A., Joubert, P.N., 2011. Numerical simulation for turbulence-driven secondary motion over a streamwise external corner. Prog. Comput. Fluid Dy. 11(1), 18-29. 
Moonen, P., Blocken, B., Roels, S., Carmeliet, J., 2006. Numerical modeling of the flow conditions in a lowspeed closed-circuit wind tunnel. J. Wind Eng. Ind. Aerodyn. 94(2): 101-127.

Moonen, P., Dorer, V., Carmeliet, J., 2011. Evaluation of the ventilation potential of courtyards and urban street canyons using RANS and LES. J. Wind Eng. Ind. Aerodyn. 99(4), 414-423.

Murakami, S., Mochida, A., 1989. Three-dimensional numerical simulation of turbulent flow around buildings using the $\mathrm{k}-\varepsilon$ turbulence model. Build. Environ. 24 (1), 51-64.

Murakami, S., Kato, S., Akabayashi, S., Mizutani, K., Kim, Y., 1991. Wind tunnel test on velocity-pressure field of cross-ventilation with open windows. ASHRAE Trans. 97, 525-538.

Neofytou, P., Venetsanos, A.G., Vlachogiannis, D., Bartzis, J.G., Scaperdas, A., 2006. CFD simulations of the wind environment around an airport terminal building. Environ. Modell. Softw. 21(4), 520-524.

Norton, T., Grant, J., Fallon, R., Sun, D.W., 2009. Assessing the ventilation effectiveness of naturally ventilated livestock buildings under wind dominated conditions using computational fluid dynamics. Biosystems Eng. 103(1), 78-99.

Norton, T., Grant, J., Fallon, R., Sun, DW., 2010. Optimising the ventilation configuration of naturally ventilated livestock buildings for improved indoor environmental homogeneity. Build. Environ. 45(4), 983-995.

Nozu, T., Tamura, T., Okuda, Y., Sanada, S., 2008. LES of the flow and building wall pressures in the center of Tokyo. J. Wind Eng. Ind. Aerodyn. 96(10-11), 1762-1773.

Oberkampf, W.L., Trucano, T.G., Hirsch, C., 2004. Verification, validation, and predictive capability in computational engineering and physics. Appl. Mech. Rev. 57(5), 345-384.

Olsen, N.R.B, 2001. CFD modeling for hydraulic structures. Department of Hydraulic and Environmental Engineering, The Norwegian University of Science and Technology, pp.37.

Parsons, D.R., Wiggs, G.F.S., Walker I.J., Ferguson, R.I., Garvey B.G., 2004. Numerical modelling of airflow over an idealised transverse dune. Environ. Modell. Softw. 19(2), 153-162.

Patankar, S.V., Spalding, D.B., 1972. A calculation procedure for heat, mass and momentum transfer in threedimensional parabolic flows. Int. J. Heat Mass Transf. 15(10), 1787-1806.

Peplinski, D.K., Ducoste, J.J., 2002. Modeling of disinfection contactor hydraulics under uncertainty. J. Environ. Eng.-ASCE 128(11), 1056-1067.

Piuleac, C.G., Rodrigo, M.A., Canizares, P., Curteanu, S., Saez, C., 2010. Ten steps modeling of electrolysis processes by using neural networks. Environ. Modell. Softw. 25, 74-81.

Pope, S.B., 2000. Turbulent flows, Cambridge University Press, Cambridge, U.K.

Ramponi, R., Blocken, B., 2012. CFD simulation of cross-ventilation for a generic isolated building: impact of computational parameters. Build. Environ. 53, 34-48.

Rauen, W.B., Lin, B., Falconer, R.A., Texeira, E.C., 2008. CFD and experimental model studies for water disinfection tanks with low Reynolds number flows. Chem. Eng. J. 137, 550-560.

Richards, P.J., Hoxey, R.P., 1993. Appropriate boundary conditions for computational wind engineering models using the k- $\varepsilon$ turbulence model. J. Wind Eng. Ind. Aerodyn. 46\&47, 145-153.

Richards, P.J., Mallison, G.D., McMillan, D., Li, Y.F., 2002. Pedestrian level wind speeds in downtown Auckland. Wind Struct. 5(2-4), 151-164.

Roache, P.J., 1997. Quantification of uncertainty in computational fluid dynamics. Annu. Rev. Fluid Mech. 29, 123-160.

Roache, P.J., 2009. Perspective: validation—what does it mean?. J. Fluid Eng.-T. ASME 131, 034503-3.

Robson, B.J., Hamilton, D.P., Webster, I.T., Chan, T., 2008. Ten steps applied to development and evaluation of process-based biogeochemical models of estuaries. Environ. Modell. Softw. 23, 369-384.

Roy, C.J, Oberkampf, W.L., 2010. A complete framework for verification, validation, and uncertainty quantification in scientific computing. 48th AIAA Aerospace Sciences Meeting Including the New Horizons Forum and Aerospace Exposition 4 - 7 January 2010, Orlando, Florida.

Rummel, A.C., Socolofsky, S.A., v. Carmer, C.F., Jirka, G.H., 2005. Enhanced diffusion from a continuous point source in shallow free-surface flow with grid turbulence. Phys. Fluids 17, 075105-1-12.

Rutherford, J.C., 1994. River mixing, John Wiley \& Sons, Chichester, U.K., pp.348.

Sandberg, M., 2004. An alternative view on the theory of cross-ventilation. Int. J. Vent. 4, 409-418.

Scaperdas, A. and Gilham, S., 2004. Thematic Area 4: Best practice advice for civil construction and HVAC, The QNET-CFD Network Newsletter, 2 (4), 28-33.

Schatzmann, M., Rafailidis, S., Pavageau, M., 1997. Some remarks on the validation of small-scale dispersion models with field and laboratory data. J. Wind Eng. Ind. Aerodyn. 67-68, 885-893.

Schatzmann, M., Leitl, B., 2011. Issues with validation of urban flow and dispersion CFD models. J. Wind Eng. Ind. Aerodyn. 99(4), 169-186.

Selvam, R.P., 1997. Computation of pressure on Texas Tech University building using large eddy simulation. J. Wind Eng. Ind. Aerodyn. 67\&68, 647-657.

Shih, T.H., Liou, W.W., Shabbir, A., Zhu, J., 1995. A new k- $\varepsilon$ eddy-viscosity model for high Reynolds number turbulent flows - model development and validation. Comput. Fluids 24(3), 227-238. 
Shiono, K., Scott, C.F., Kearney, D., 2003. Predictions of solute transport in a compound channel using turbulence models. J. Hydraul. Res. 41(3), 47-258.

Solazzo, E., Cai, X., Vardoulakis, S., 2009. Improved parameterisation for the numerical modelling of air pollution within an urban street canyon. Environ. Modell. Softw. 24(3), 381-388.

Sorensen, DN, Nielsen, PV. 2003. Quality control of computational fluid dynamics in indoor environments. Indoor Air 13(1), 2-17.

Sotiropoulos, F., 2005. Introduction to statistical turbulence modeling for hydraulic engineering flows, in Bates, P.D., Lane, S.N., and Ferguson, R.I., (Eds) "Computational Fluid Dynamics. Applications in Environmental Hydraulics", John Wiley \& Sons, Chichester, England, pp.534.

Stamou, A.I., 2008. Improving the hydraulic efficiency of water process tanks using CFD models. Chem. Eng. Process. 47, 1179-1189.

Stathopoulos, T., 1997. Computational wind engineering: Past achievements and computational challenges. J. Wind Eng. Ind. Aerodyn., 67-68, 509-532.

Stathopoulos, T., Baskaran, A., 1990. Boundary treatment for the computation of 3D turbulent conditions around buildings. J. Wind Eng. Ind. Aerodyn. 35, 177-200.

Stern, F., Wilson, R.V., Coleman, H.W., 2001. Comprehensive approach to verification and validation of CFD simulations-Part 1: Methodology and procedures. J. Fluid Eng.-T. ASME 123, 793-802.

Tamura, T., Kawai, H., Kawamoto, S., Nozawa, K., Sakamoto, S., Ohkuma, T., 1997. Numerical prediction of wind loading on buildings and structures - Activities of AIJ cooperative project on CFD. J. Wind Eng. Ind. Aerodyn. 67-68, 671-685.

Tamura, T., Nozawa, K., Kondo, K., 2008. AIJ guide for numerical prediction of wind loads on buildings. J. Wind Eng. Ind. Aerodyn. 96(10-11), 1974-1984.

Tang, W., Davidson, C.I., 2004. Erosion of limestone building surfaces caused by wind-driven rain. 2. Numerical modelling. Atmos. Environ. 38(33), 5601-5609.

Tominaga, Y., Murakami, S., Mochida, A., 1997. CFD prediction of gaseous diffusion around a cubic model using a dynamic mixed SGS model based on composite grid technique. J. Wind Eng. Ind. Aerodyn. 67-68, 827-841.

Tominaga, Y., Mochida, A., 1999. CFD prediction of flowfield and snowdrift around a building complex in a snowy region. J. Wind Eng. Ind. Aerodyn. 81(1-3), 273-282.

Tominaga, Y., Mochida, A., Murakami, S., Sawaki, S., 2008a. Comparison of various revised k- $\varepsilon$ models and LES applied to flow around a high-rise building model with 1:1:2 shape placed within the surface boundary layer. J. Wind Eng. Ind. Aerodyn. 96(4), 389-411.

Tominaga, Y., Mochida, A., Yoshie, R., Kataoka, H., Nozu, T., Yoshikawa, M., Shirasawa, T., 2008b. AIJ guidelines for practical applications of CFD to pedestrian wind environment around buildings. J. Wind Eng. Ind. Aerodyn. 96(10-11), 1749-1761.

Tominaga, Y., Stathopoulos, T., 2009. Numerical simulation of dispersion around an isolated cubic building: Comparison of various types of k- $\varepsilon$ models. Atmos. Environ. 43(20), 3200-3210.

Tominaga, Y., Stathopoulos, T., 2010. Numerical simulation of dispersion around an isolated cubic building: Model evaluation of RANS and LES. Build. Environ. 45(10), 2231-2239.

Tominaga, Y., Stathopoulos, T., 2011. CFD modeling of pollution dispersion in a street canyon: Comparison between LES and RANS. J. Wind Eng. Ind. Aerodyn. 99(4), 340-348.

Tominaga, Y., Okaze, T., Mochida, A., 2011. CFD modeling of snowdrift around a building: An overview of models and evaluation of a new approach. Build. Environ. 46: 899-910.

Tsutsumi, J., Katayama, T., Ishii, A., He, P., Hayashi, T., 1996. Investigation and numerical simulation of the wind effects on thermal comfort in a house. J. Wind Eng. Ind. Aerodyn. 60, 267-280.

Tucker, P.G., Mosquera, A., 2001. NAFEMS introduction to grid and mesh generation for CFD. NAFEMS CFD Working Group, R0079, 56 pp.

van Hooff, T., Blocken, B., 2010a. Coupled urban wind flow and indoor natural ventilation modelling on a highresolution grid: A case study for the Amsterdam ArenA stadium. Environ. Modell. Softw. 25(1), 51-65.

van Hooff, T., Blocken, B., 2010b. On the effect of wind direction and urban surroundings on natural ventilation of a large semi-enclosed stadium. Comput. Fluids 39, 1146-1155.

van Hooff, T., Blocken, B., van Harten, M., 2011a. 3D CFD simulations of wind flow and wind-driven rain shelter in sports stadia: influence of stadium geometry. Build. Environ. 46(1), 22-37

van Hooff, T., Blocken, B., Aanen, L., Bronsema, B., 2011b. A venturi-shaped roof for wind-induced natural ventilation of buildings: wind tunnel and CFD evaluation of different design configurations. Build. Environ. 46(9), 1797-1807.

van Mook, F.J.R., 2002. Driving rain on building envelopes, Ph.D. thesis, Building Physics and Systems, Eindhoven University of Technology, Eindhoven University Press, Eindhoven, The Netherlands, 198 p.

Van Prooijen, B.C., Uijttewaal, W.S.J., 2005. Horizontal mixing in shallow flows, in Czernuszenko, W., and Rowinski, P. (Eds), Water Quality Hazards and Dispersion of Pollutants, Springer Science+Business Inc., New York, NY, USA, pp. 250 
Wakes, S.J., Maegli, T., Dickinson, K.J., Hilton, M.J., 2010. Numerical modelling of wind flow over a complex topography. Environ. Modell. Softw. 25(2), 237-247.

Welsh, W.D., 2008. Water balance modelling in Bowen, Queensland, and the ten iterative steps in model development and evaluation. Environ. Modell. Softw. 23, 195-205.

Wieringa, J., 1992. Updating the Davenport roughness classification. J. Wind Eng. Ind. Aerodyn. 41-44, 357-368.

Wilcox, D.C., 1998. Turbulence modeling for CFD. La Canada, California: DCW Industries, Inc.

Wols, B.A., Hofman, J.A.M.H., Uijttewaal, W.S.J., Rietveld, L.C., van Dijk, J.C., 2010. Evaluation of different disinfection calculation methods using CFD. Environ. Modell. Softw. 25(4), 573-582.

Won Seo, I., Park, S.W., Song, C.G., 2009. Two dimensional experimental and numerical analyses of flow and pollutant transport in meandering channel. Int. Workshop Environmental Hydraulics: Theoretical, Experimental \& Computational Solutions (IWEH 2009), Valencia, Spain, October 29/30.

Wright, N.G., Hargreaves D.M., 2006. Unsteady CFD simulations for natural ventilation. Int. J. Vent. 5(1), 13-20.

Wakes, S.J., Maegli, T., Dickinson, K.J., Hilton, M.J., 2010. Numerical modelling of wind flow over a complex topography. Environ. Modell. Softw. 25(2), 237-247.

Yang, Y., Shao, Y., 2008. Numerical simulations of flow and pollution dispersion in urban atmospheric boundary layers. Environ. Modell. Softw. 23(7), 906-921.

Yang, Y., Gu, M., Chen, S., Jin, X., 2009. New inflow boundary conditions for modelling the neutral equilibrium atmospheric boundary layer in computational wind engineering. J. Wind Eng. Ind. Aerodyn. 97 (2), 88-95.

Yoshie, R., Mochida, A., Tominaga, Y., Kataoka, H., Harimoto, K., Nozu, T., Shirasawa, T., 2007. Cooperative project for CFD prediction of pedestrian wind environment in the Architectural Institute of Japan. J. Wind Eng. Ind. Aerodyn. 95 (9-11), 1551-1578.

Zhang, M., Shen, Y., 2008. Three-dimensional simulation of meandering river based on 3D RNG k- $\varepsilon$ turbulence model, J. Hydrodyn. 20 (4), 448-455. 


\section{FIGURES}

(a)

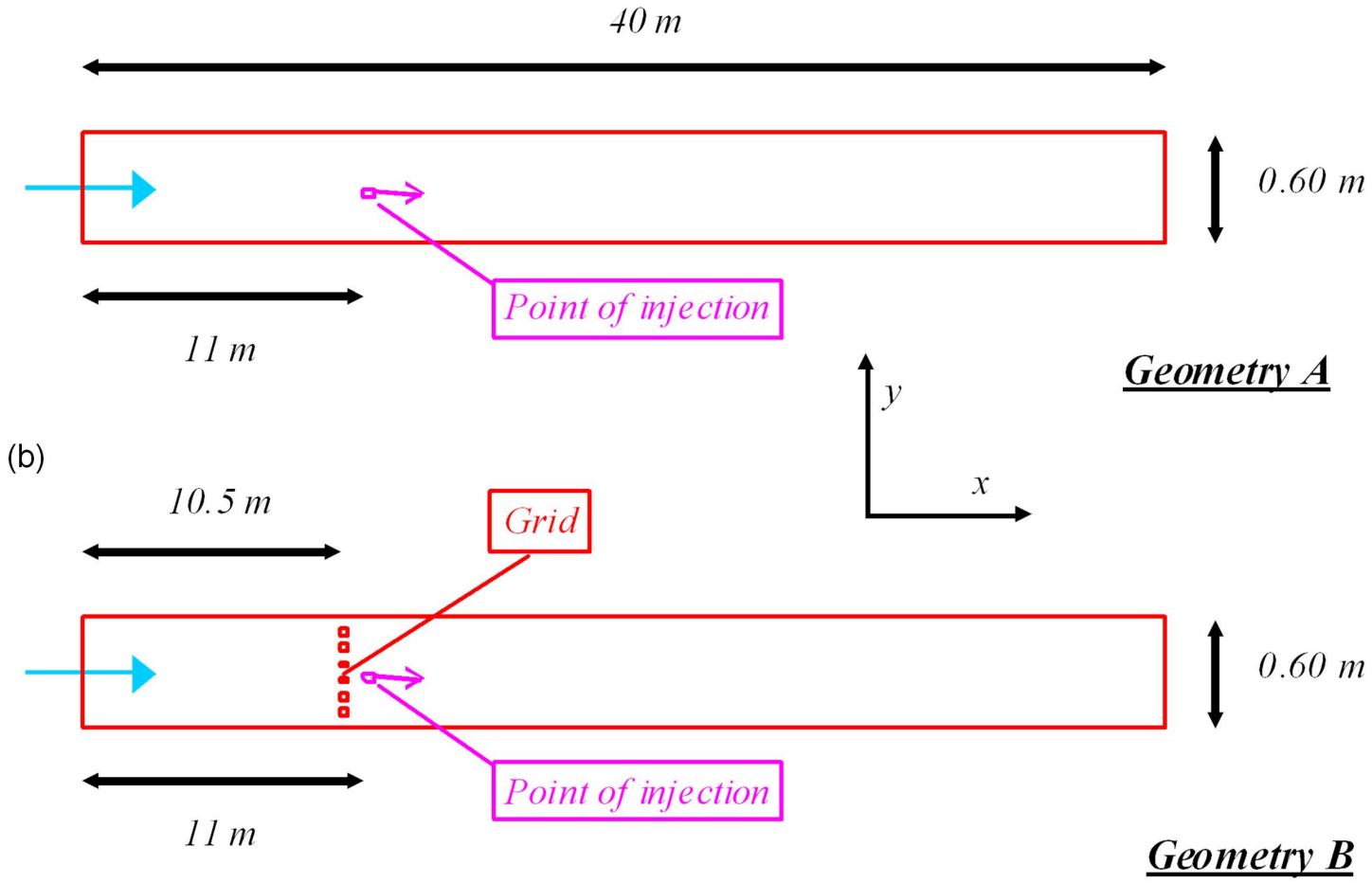

Figure 1. Geometries used in the numerical study on transverse turbulent mixing: (a) Geometry A and (b) Geometry B with grid composed of six square elements.

(a)
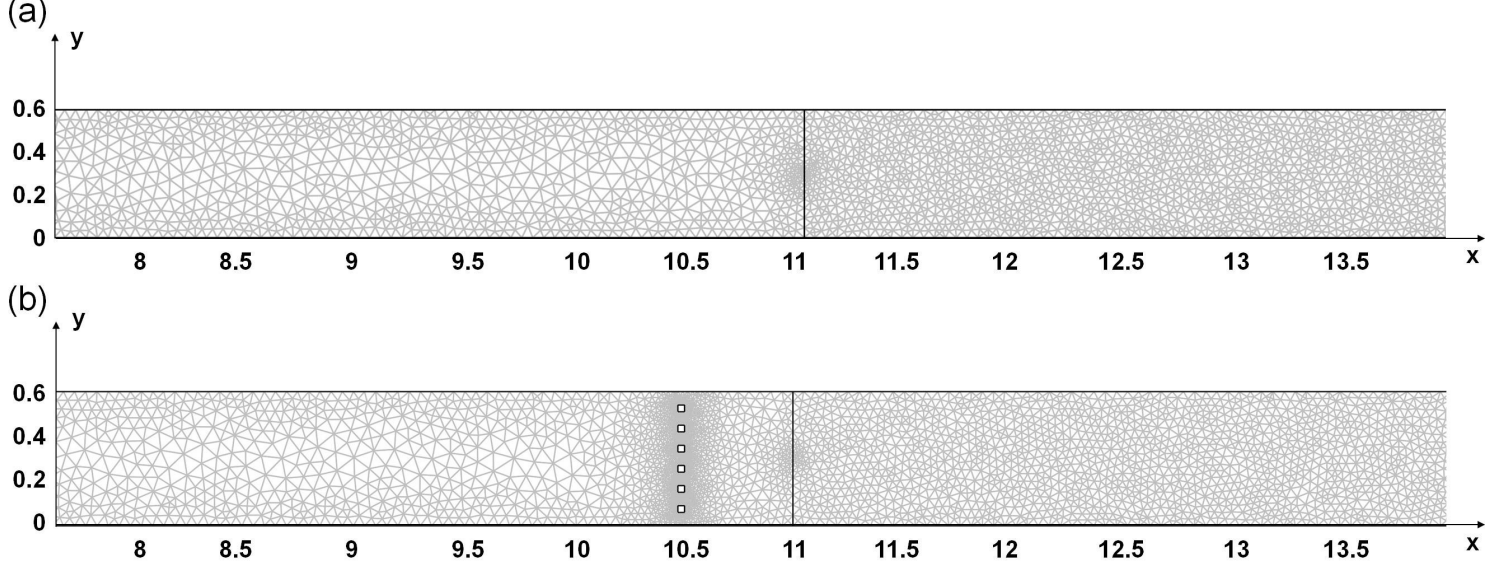

Figure 2. Mesh for (a) Geometry A (35124 elements) and (b) Geometry B (37284 elements). Dimensions in m. 


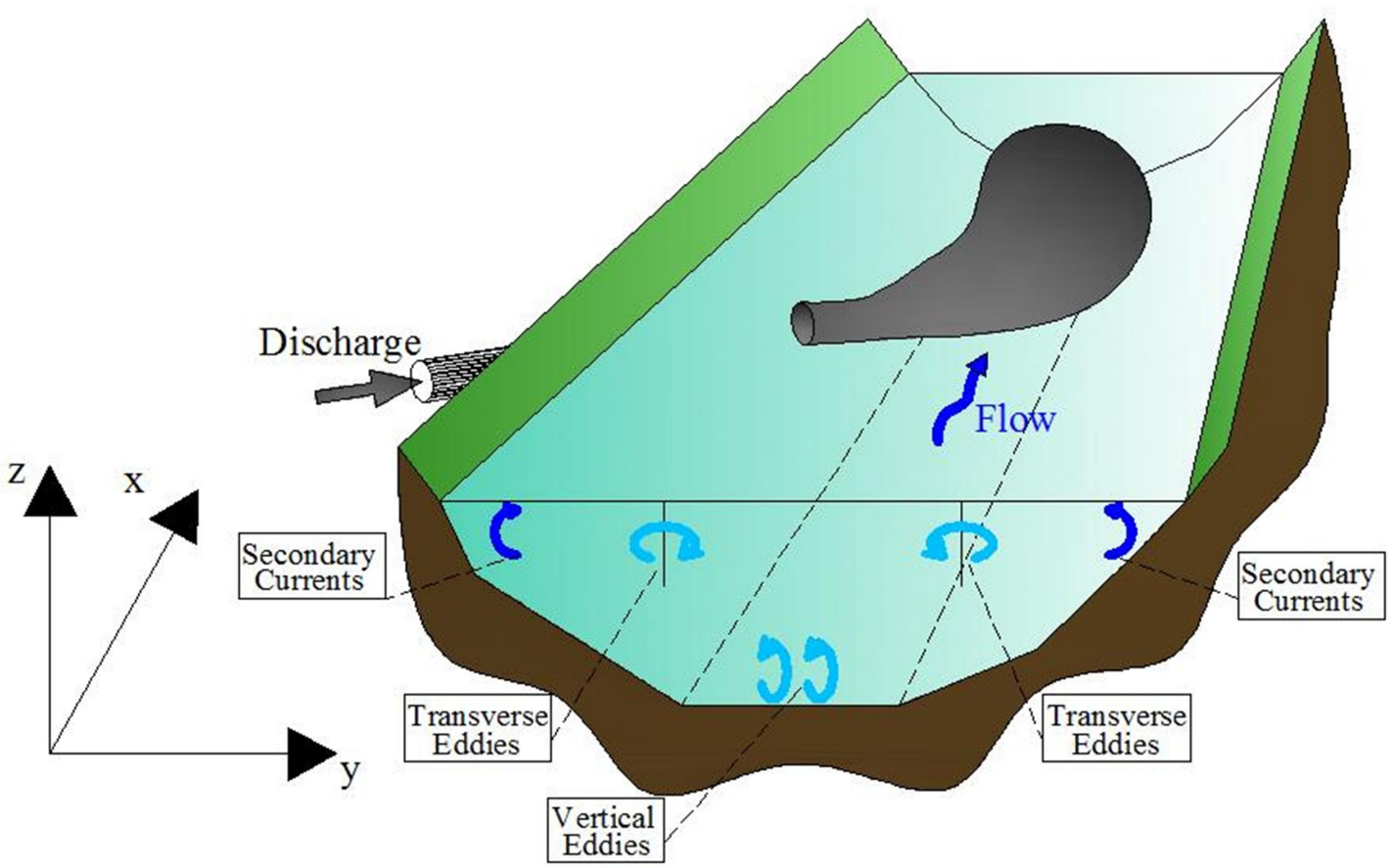

Figure 3. Sketch of transverse mixing in a natural channel (Gualtieri 2010)

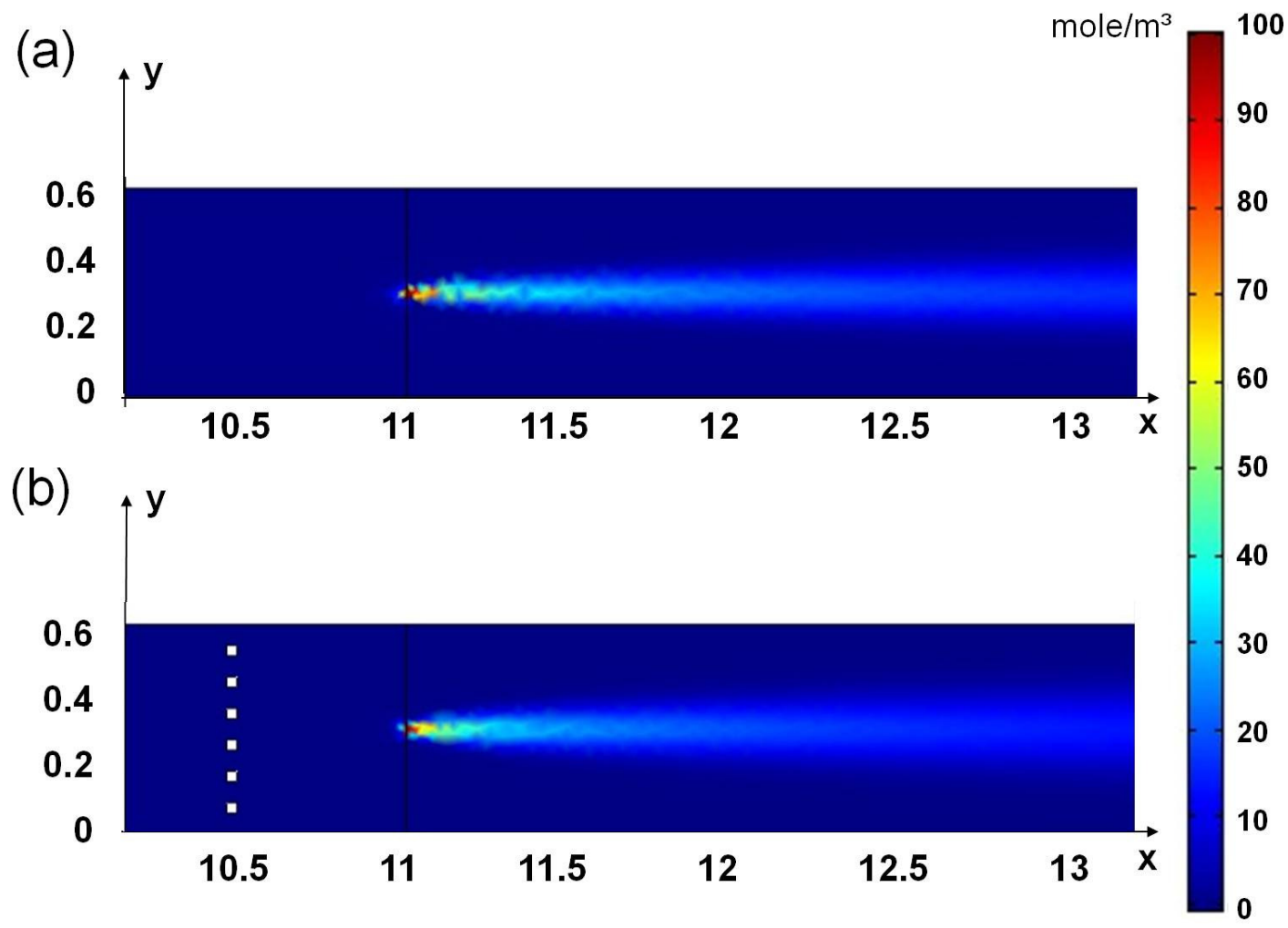

Figure 4. Concentration field in (a) geometry A and (b) geometry B. Dimensions in $\mathrm{m}$ (Gualtieri 2010). $\mathrm{x}=0 \mathrm{~m}$ is the inlet of the computational domain. 
(a)

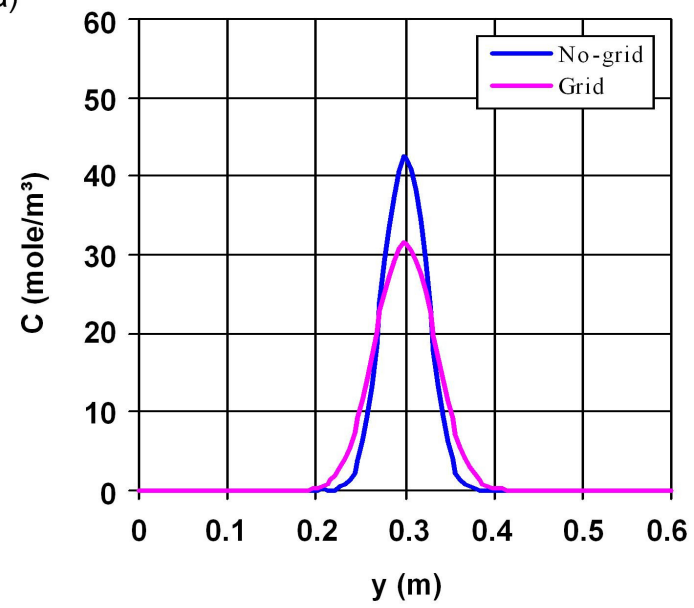

(b)

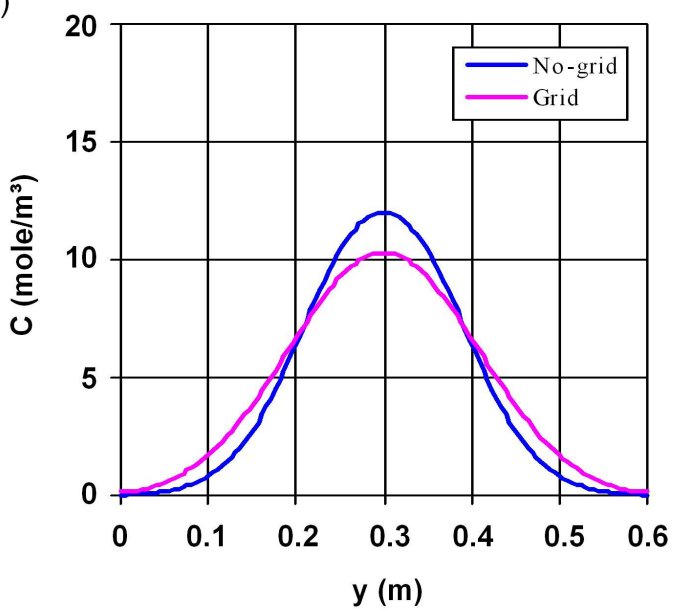

Figure 5. Concentration field transverse distributions at (a) $x=11.25 \mathrm{~m}$ (b) and $\mathrm{x}=15.00 \mathrm{~m}$ (Gualtieri 2010), for two situations: without and with a grid in the flow to enhance mixing.

(a)

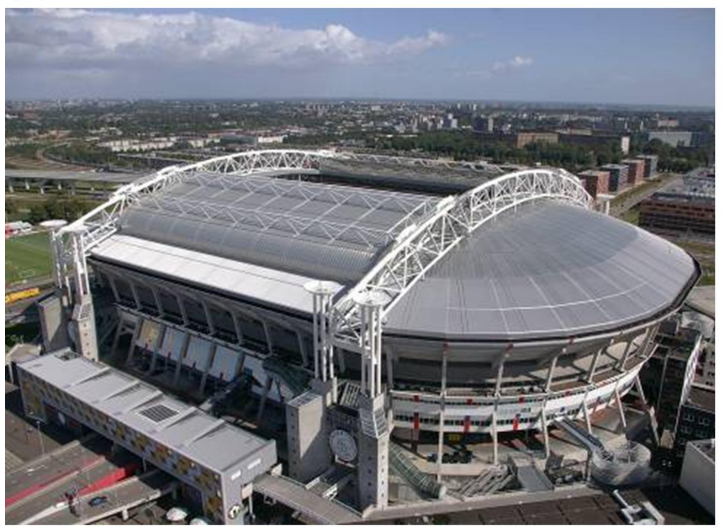

(c)

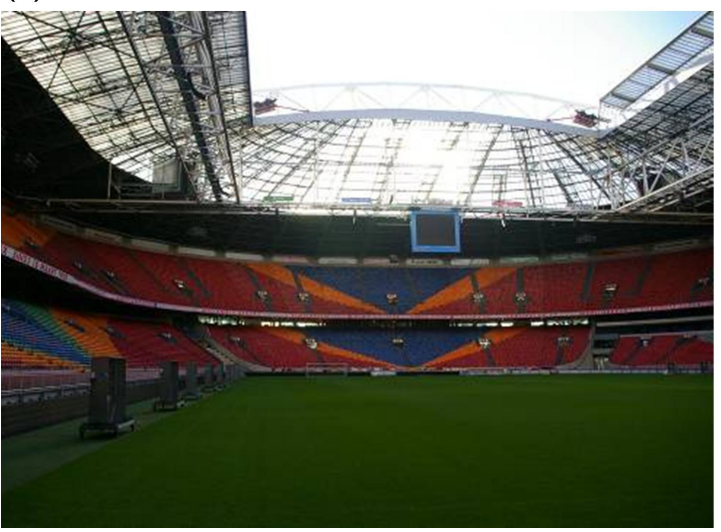

(b)

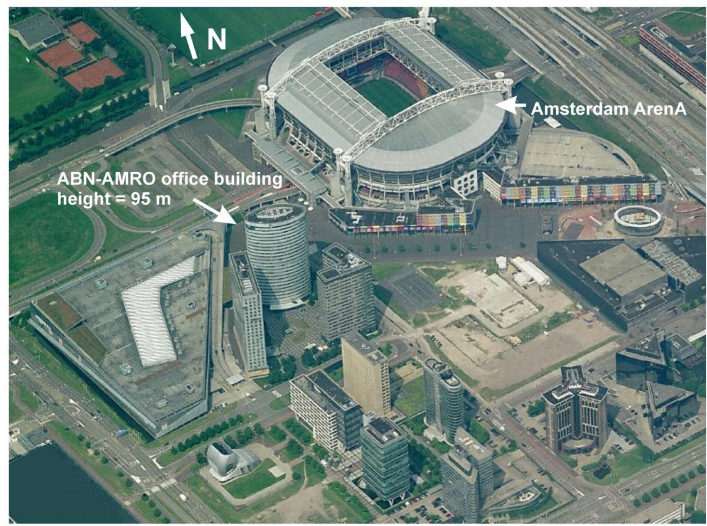

(d)

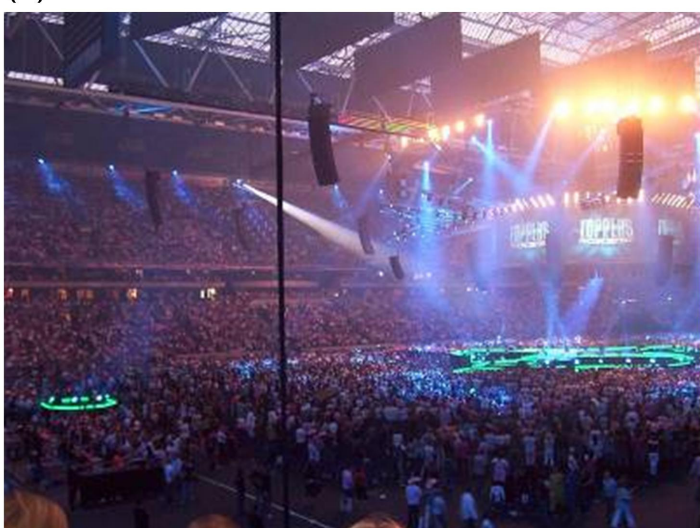

Figure 6. Amsterdam ArenA stadium: (a) Aerial view of stadium with roof opened; (b) Stadium and surrounding high-rise and low-rise buildings; (c) View from the stadium interior showing roof with steel trusses and polycarbonate roof sheets (roof opened); (d) View from stadium interior during concert (roof closed) (van Hooff and Blocken 2010a). 
(a)

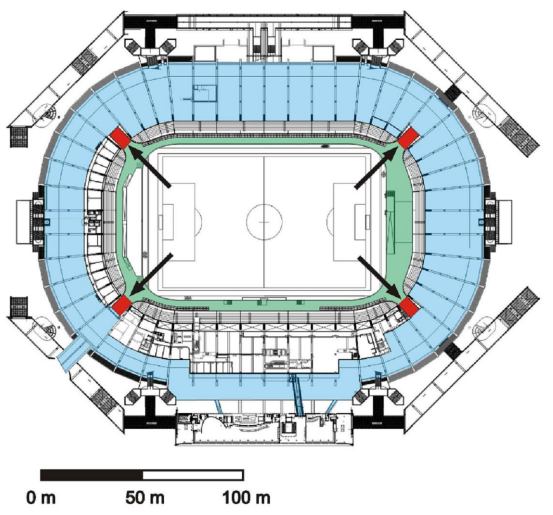

(c)

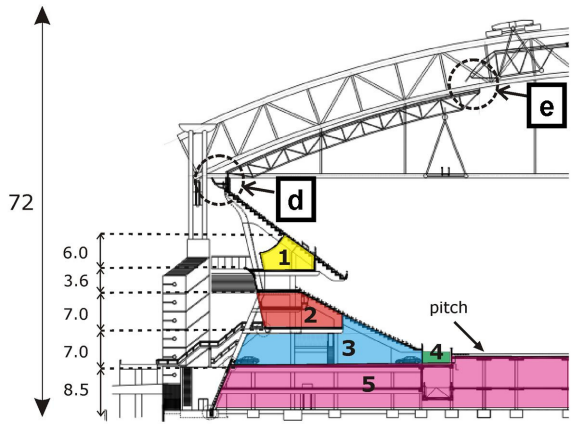

(b)

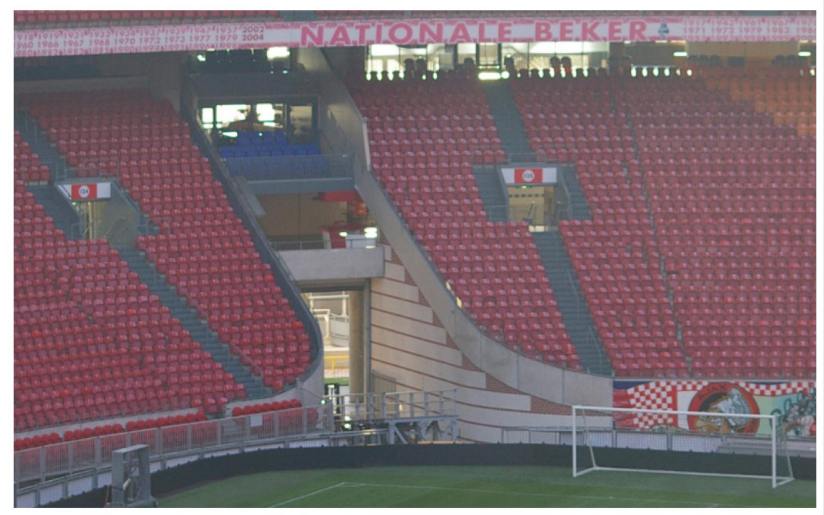

(d)

(e)

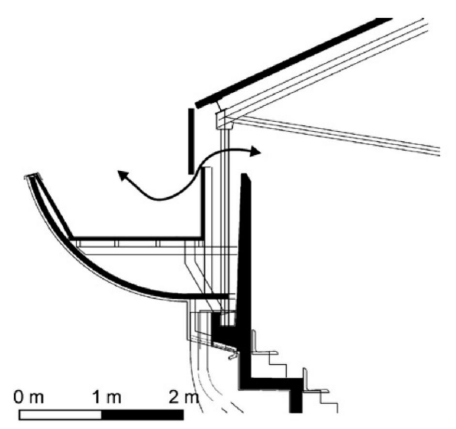

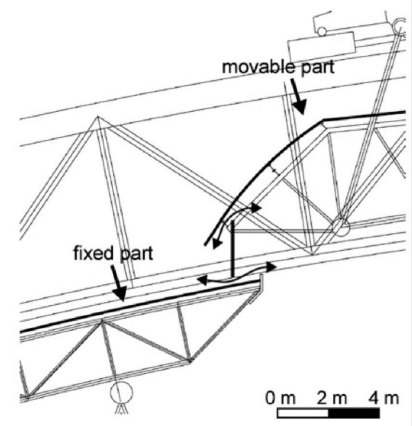

Figure 7. Amsterdam ArenA stadium: (a) Ground plan with indication of the four gates; (b) View at one of the gates from stadium interior; (c) Vertical cross-section of stadium with indication of ventilation openings labeled with "d" and "e"; (d) Ventilation opening "d" near roof gutter; (e) Ventilation opening "e" between fixed and movable part of the roof (van Hooff and Blocken 2010a). 
(a)

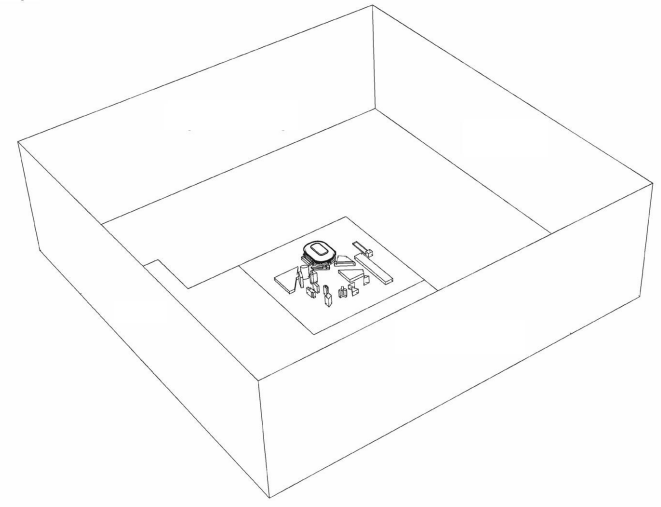

(c)

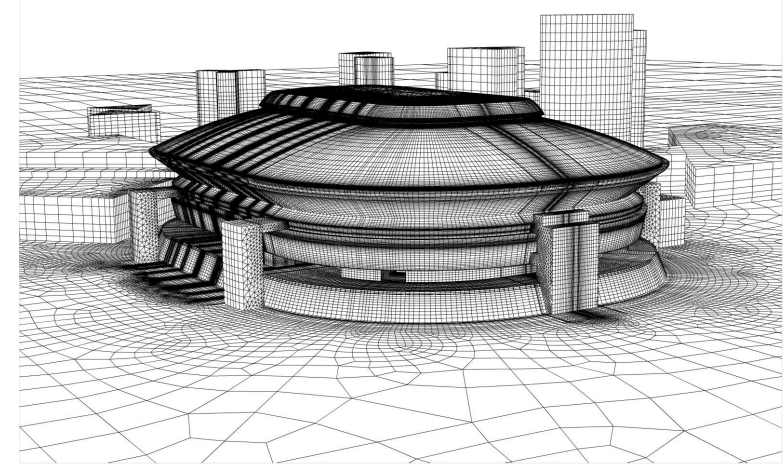

(b)

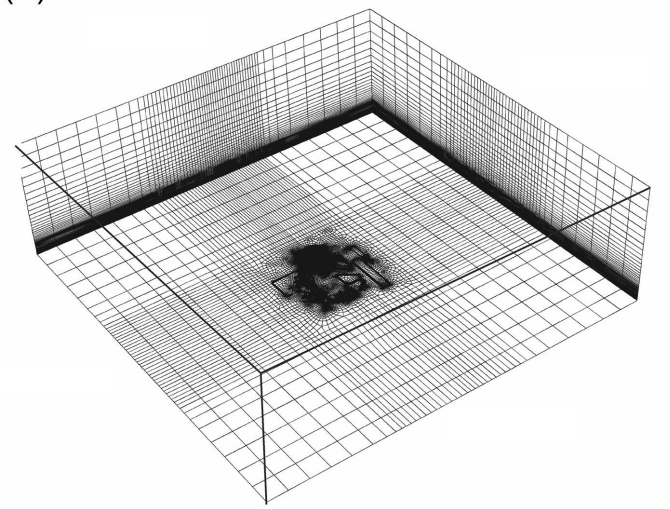

(d)

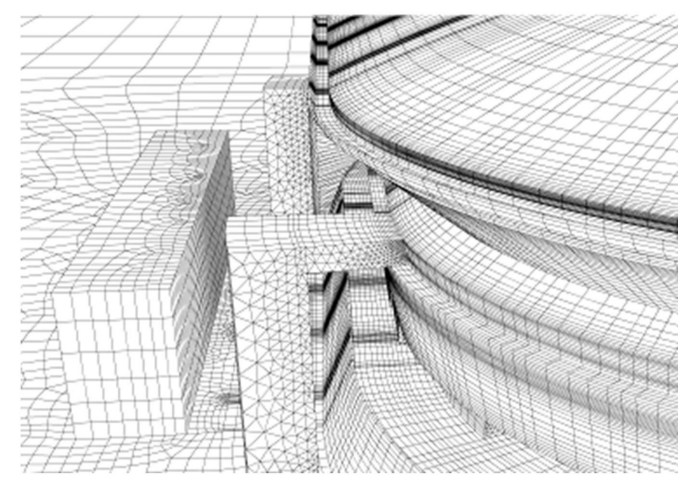

Figure 8. (a) Computational domain; (b) Computational domain and mesh; (c) Computational mesh - view from north (5.6 x $10^{6}$ control volumes); (d) Detail of computational mesh near roof gutter (van Hooff and Blocken 2010a).

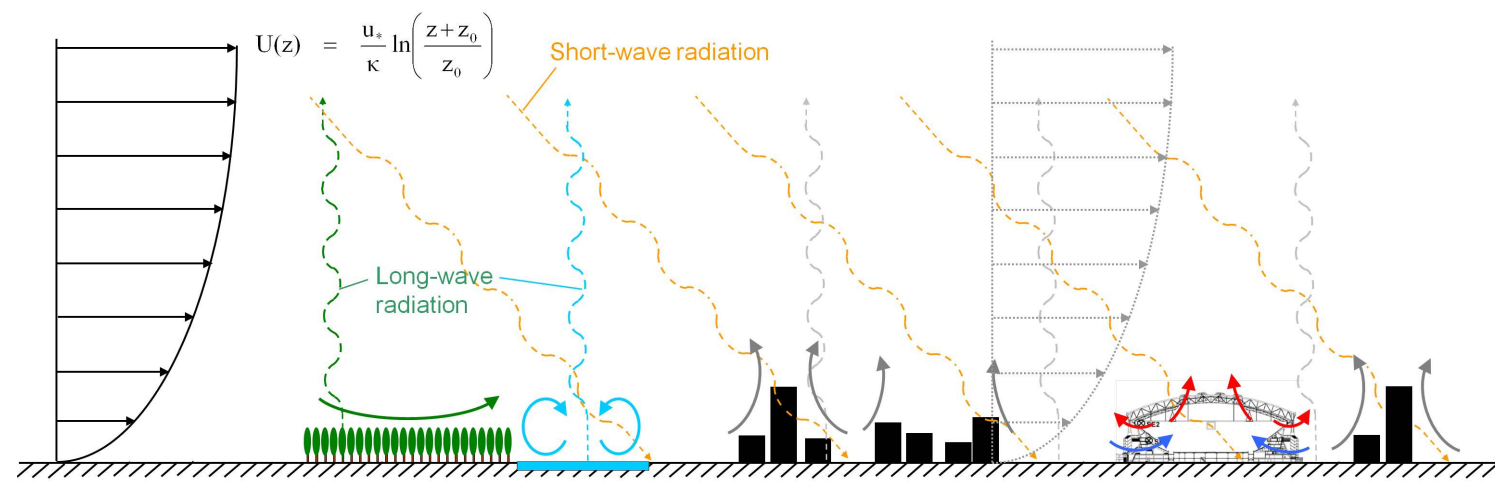

Figure 9. Conceptualization of urban wind flow and indoor natural ventilation of the Amsterdam ArenA stadium. Solid lines indicate convective heat and mass transfer, dashed lines indicate short-wave and long-wave radiative heat transfer. 


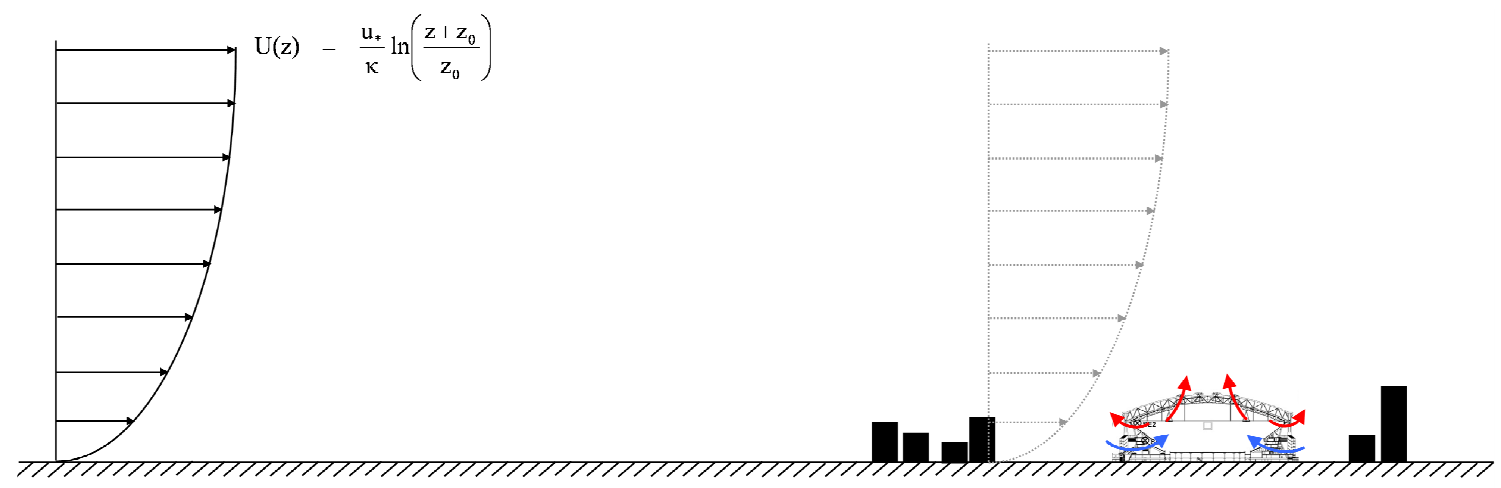

Figure 10. Conceptualization after implementation of simplifications

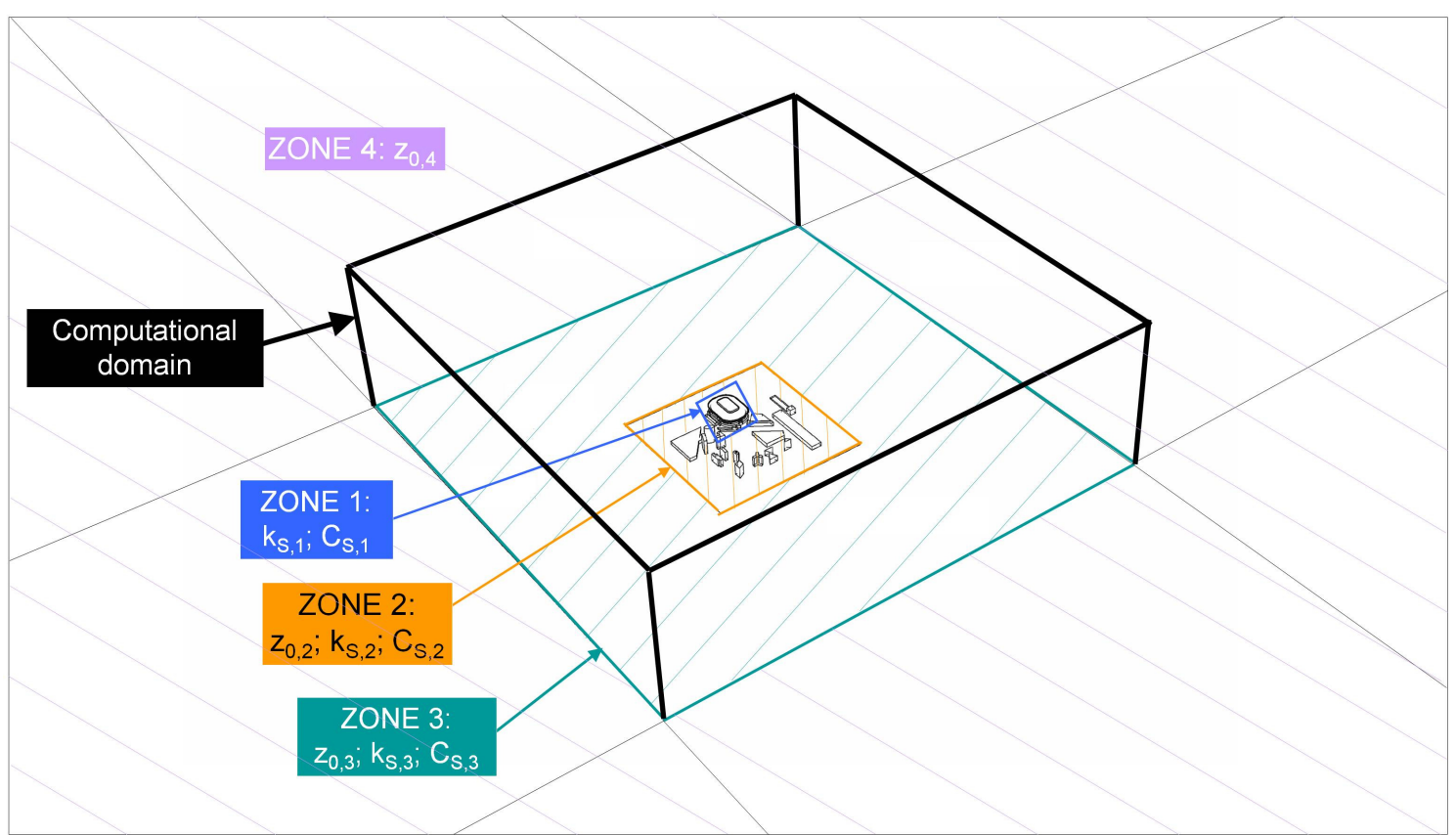

Figure 11. Four zones of spatial resolution modeling and related roughness parameters

a

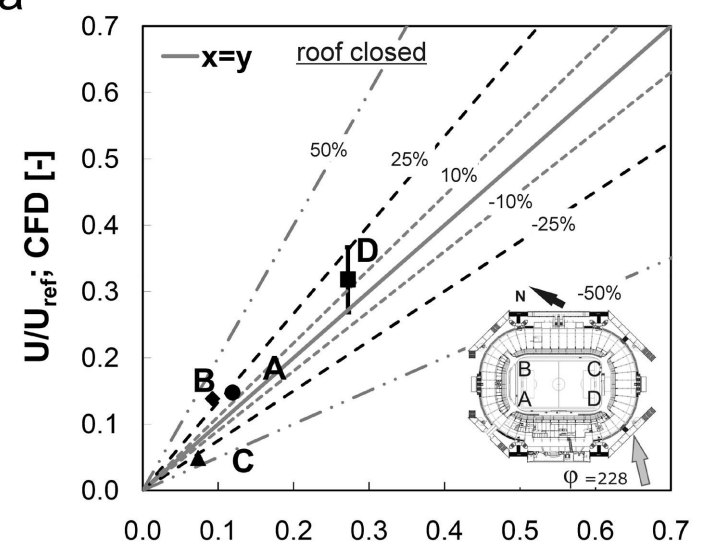

b

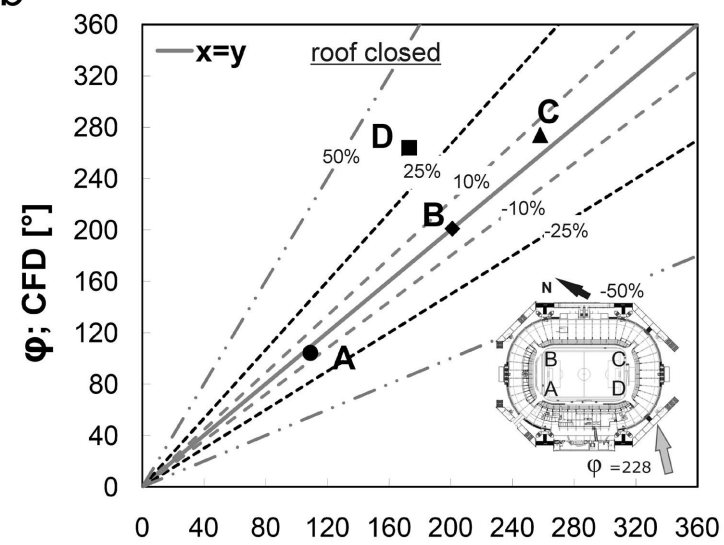

Figure 12. Comparison between numerical and experimental results in the four gates A, B, C and D, for closed roof and south-west wind direction $228^{\circ}$; (a) Non-dimensional velocity magnitude $U / \mathrm{U}_{\text {ref }}$, (b) Wind direction $\varphi$. The error bars are a measure of the local spatial gradients in the CFD simulation (van Hooff and Blocken 2010a). 
a

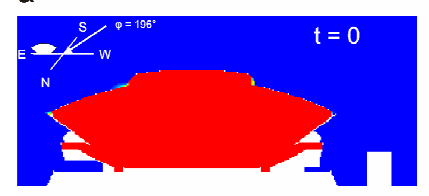

d

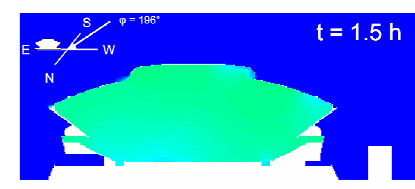

b

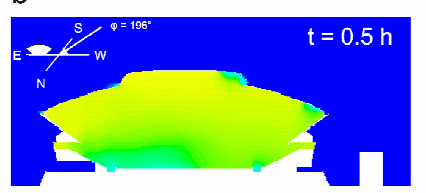

e

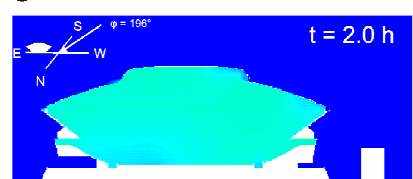

c

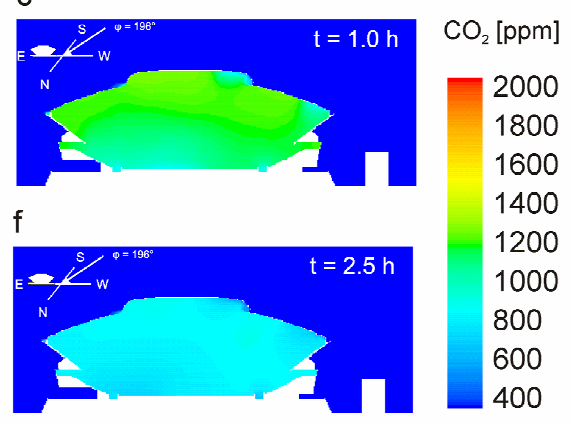

Figure 13. Simulated contours of $\mathrm{CO}_{2}$ concentration in a vertical cross-section through the stadium, at six different positions in time following the end of a concert, when natural ventilation causes the indoor concentration to gradually decrease. 